\title{
Taking account of context in population health intervention research: guidance for producers, users and funders of research
}

\author{
Peter Craig, ${ }^{1 *}$ Erica Di Ruggiero, ${ }^{2}$ \\ Katherine L Frohlich, ${ }^{3}$ Eric Mykhalovskiy ${ }^{4}$ and \\ Martin White ${ }^{5}$ on behalf of the Canadian Institutes \\ of Health Research (CIHR)-National Institute for \\ Health Research (NIHR) Context Guidance Authors \\ Group (listed alphabetically): Rona Campbell, ${ }^{6}$ \\ Steven Cummins, ${ }^{7}$ Nancy Edwards, ${ }^{8}$ Kate Hunt, ${ }^{1}$ \\ Frank Kee, ${ }^{9}$ Charlotte Loppie, ${ }^{10}$ Laurence Moore, ${ }^{1}$ \\ David Ogilvie, ${ }^{5}$ Mark Petticrew, ${ }^{11}$ Blake Poland, ${ }^{2}$ \\ Valéry Ridde, 12,13,14 Jeannie Shoveller, ${ }^{15}$ \\ Sarah Viehbeck ${ }^{16,17}$ and Daniel Wight ${ }^{1}$
}

${ }^{1}$ Medical Research Council (MRC)/Chief Scientist Office (CSO) Social and Public Health Sciences Unit, University of Glasgow, Glasgow, UK

2Dalla Lana School of Public Health, University of Toronto, Toronto, ON, Canada

${ }^{3}$ École de Santé Publique and University of Montréal Public Health Research Institute (IRSPUM), Université de Montréal, Montréal, QC, Canada

${ }^{4}$ Department of Sociology, York University, Toronto, ON, Canada

${ }^{5}$ Centre for Diet and Activity Research, Medical Research Council (MRC)

Epidemiology Unit, University of Cambridge, Cambridge, UK

${ }^{6}$ Department of Population Health Sciences, University of Bristol, Bristol, UK

${ }^{7}$ Department of Social and Environmental Health, London School of Hygiene \& Tropical Medicine, London, UK

${ }^{8}$ Faculty of Health Sciences, University of Ottawa, Ottawa, ON, Canada

9UK Clinical Research Collaboration (UKCRC) Centre of Excellence for Public Health Research, Queen's University Belfast, Belfast, UK

${ }^{10}$ Faculty of Human and Social Development, University of Victoria, Victoria, BC, Canada

${ }^{11}$ Faculty of Public Health and Policy, London School of Hygiene \& Tropical Medicine, London, UK 


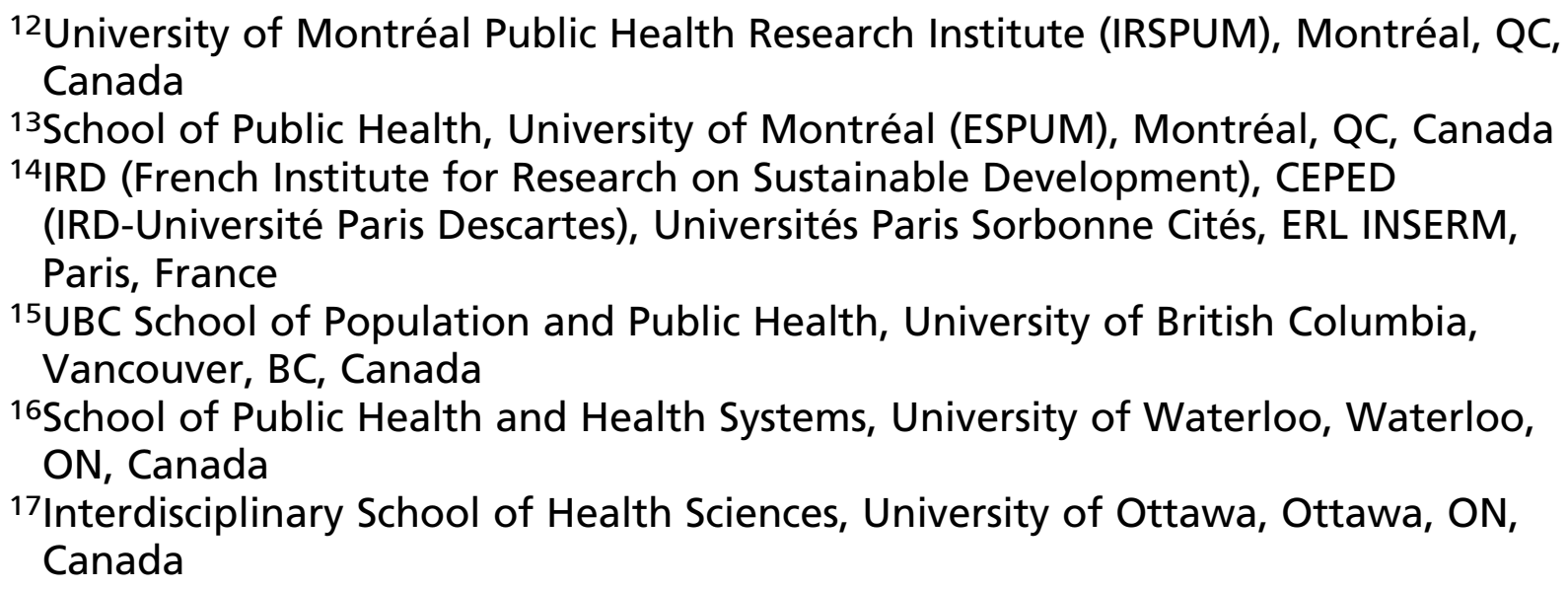

*Corresponding author

Declared competing interests of authors: Martin White is Director of the National Institute for Health Research (NIHR) Public Health Research programme (2014-19) and a NIHR Senior Investigator. He is supported by the Centre for Diet and Activity Research in the Medical Research Council (MRC) Epidemiology Unit, University of Cambridge, which received funding from the British Heart Foundation, Cancer Research UK, Economic and Social Research Council, MRC, NIHR and Wellcome Trust. He reports grants from the MRC and NIHR for research reported in case studies in this report. Frank Kee is Chair of the NIHR Public Health Research programme Research Funding Board. Rona Campbell, Steven Cummins, Kate Hunt and Laurence Moore were members of the NIHR Public Health Research programme Research Funding Board for periods during the life of this project. Erica Di Ruggiero, Nancy Edwards and Sarah Viehbeck held positions with the Canadian Institutes of Health Research - Institute of Population and Public Health (CIHR-IPPH) for periods during the life of this project. Mark Petticrew was a member of the CIHR International Advisory Board, CIHR-IPPH, for a period during the life of this project. Rona Campbell reports having been appointed NIHR Senior Investigator and Deputy Director of the NIHR School for Public Health Research during the life of this project. She reports grants from the British Heart Foundation, Cancer Research UK, Economic and Social Research Council, UK MRC, Welsh Government and Wellcome Trust, under the auspices of the UK Clinical Research Collaboration that funded research reported in a case study in this report. Peter Craig reports core funding and awards from the MRC and the Scottish Government Chief Scientist Office (CSO) under award codes MC_UU_12017-15 and SPHSU15 respectively. Nancy Edwards reports a grant from the CIHR and International Development Research Centre that was the basis for a case study included in this report. Kate Hunt reports being a member of the UK MRC Population Health Intervention Development scheme and a member of the UK MRC Population and Systems Medicine Board during the life of this project. She reports funding from the MRC and the Scottish Government CSO for a programme of research on 'Understanding and Improving Health within Settings and Organisation' and a grant from the NIHR Public Health Research programme. Kate Hunt was also Deputy Chair for the UK NIHR Public Health Research programme Research Funding Board during part of the time that this paper was being developed and written. Charlotte Loppie reports a grant from the CIHR that funded research reported in a case study in this report. Laurence Moore reports having been a member of the UK MRC Population Health Strategy Group and the MRC/NIHR Methodology Research Programme Panel during the life of this project. He also reports core funding from the MRC and the Scottish Government CSO. David Ogilvie reports a grant from the NIHR Public Health Research programme and a grant from the MRC programme during the life of the project. Mark Petticrew reports a grant from the NIHR to develop a briefing paper. Valéry Ridde reports conducting consultancy work for non-governmental organisations implementing the user fees exemption intervention in West Africa. Daniel Wight reports grants from the UK MRC and the NIHR. Outside the submitted work, he reports core funding from the UK MRC to lead a theme of research on the transferability of interventions.

Published April 2018

DOI: 10.3310/CIHR-NIHR-01 
This report should be referenced as follows:

Craig P, Di Ruggiero E, Frohlich KL, Mykhalovskiy E and White M, on behalf of the Canadian Institutes of Health Research (CIHR)-National Institute for Health Research (NIHR) Context Guidance Authors Group. Taking account of context in population health intervention research: guidance for producers, users and funders of research. Southampton: NIHR Evaluation, Trials and Studies Coordinating Centre; 2018. 



\section{This report}

This report is the output from a collaboration between the Canadian Institutes of Health Research (CIHR) - Institute of Population and Public Health (IPPH) and the UK National Institute for Health Research (NIHR). The report provides guidance on taking context into account in population health intervention research (PHIR) for producers, users and funders of population health intervention research (PHIR). The report includes international case examples to help researchers to think about dimensions of context that might be significant in population health interventions. The work was funded by CIHR - IPPH and NIHR. The authors have been wholly responsible for all data collection, analysis and interpretation, and for writing up their work.

The views expressed in this report are those of the authors and do not necessarily represent those of CIHR or its Institute of Population and Public Health (IPPH), NIHR or the UK Department of Health.

(c) Queen's Printer and Controller of HMSO 2018. This work was produced by Craig et al. under the terms of a commissioning contract issued by the Secretary of State for Health and Social Care. This issue may be freely reproduced for the purposes of private research and study and extracts (or indeed, the full report) may be included in professional journals provided that suitable acknowledgement is made and the reproduction is not associated with any form of advertising. Applications for commercial reproduction should be addressed to: NIHR Journals Library, National Institute for Health Research, Evaluation, Trials and Studies Coordinating Centre, Alpha House, University of Southampton Science Park, Southampton SO16 7NS, UK.

Published by the NIHR Journals Library (www.journalslibrary.nihr.ac.uk), produced by Prepress Projects Ltd, Perth, Scotland (www.prepress-projects.co.uk). 



\title{
Abstract
}

\section{Taking account of context in population health intervention research: guidance for producers, users and funders of research}

\author{
Peter Craig, ${ }^{1 *}$ Erica Di Ruggiero, ${ }^{2}$ Katherine L Frohlich, ${ }^{3}$ \\ Eric Mykhalovskiy ${ }^{4}$ and Martin White ${ }^{5}$ on behalf of the Canadian \\ Institutes of Health Research (CIHR)-National Institute for Health \\ Research (NIHR) Context Guidance Authors Group (listed \\ alphabetically): Rona Campbell, ${ }^{6}$ Steven Cummins, ${ }^{7}$ Nancy Edwards, ${ }^{8}$ \\ Kate Hunt, ${ }^{1}$ Frank Kee, ${ }^{9}$ Charlotte Loppie, ${ }^{10}$ Laurence Moore, ${ }^{1}$ \\ David Ogilvie, ${ }^{5}$ Mark Petticrew, ${ }^{11}$ Blake Poland, ${ }^{2}$ Valéry Ridde, $12,13,14$ \\ Jeannie Shoveller, ${ }^{15}$ Sarah Viehbeck ${ }^{16,17}$ and Daniel Wight ${ }^{1}$
}

${ }^{1}$ Medical Research Council (MRC)/Chief Scientist Office (CSO) Social and Public Health Sciences Unit, University of Glasgow, Glasgow, UK

2Dalla Lana School of Public Health, University of Toronto, Toronto, ON, Canada

3École de Santé Publique and University of Montréal Public Health Research Institute (IRSPUM), Université de Montréal, Montréal, QC, Canada

${ }^{4}$ Department of Sociology, York University, Toronto, ON, Canada

${ }^{5}$ Centre for Diet and Activity Research, Medical Research Council (MRC) Epidemiology Unit, University of Cambridge, Cambridge, UK

6Department of Population Health Sciences, University of Bristol, Bristol, UK

${ }^{7}$ Department of Social and Environmental Health, London School of Hygiene \& Tropical

Medicine, London, UK

${ }^{8}$ Faculty of Health Sciences, University of Ottawa, Ottawa, ON, Canada

9UK Clinical Research Collaboration (UKCRC) Centre of Excellence for Public Health Research,

Queen's University Belfast, Belfast, UK

${ }^{10}$ Faculty of Human and Social Development, University of Victoria, Victoria, BC, Canada

${ }^{11}$ Faculty of Public Health and Policy, London School of Hygiene \& Tropical Medicine, London, UK 12University of Montréal Public Health Research Institute (IRSPUM), Montréal, QC, Canada

${ }^{13}$ School of Public Health, University of Montréal (ESPUM), Montréal, QC, Canada

${ }^{14}$ IRD (French Institute for Research on Sustainable Development), CEPED (IRD-Université Paris

Descartes), Universités Paris Sorbonne Cités, ERL INSERM, Paris, France

15UBC School of Population and Public Health, University of British Columbia, Vancouver,

BC, Canada

${ }^{16}$ School of Public Health and Health Systems, University of Waterloo, Waterloo, ON, Canada

17Interdisciplinary School of Health Sciences, University of Ottawa, Ottawa, ON, Canada

*Corresponding author Peter.Craig@glasgow.ac.uk

Population health intervention research (PHIR) seeks to develop and evaluate policies, programmes and other types of interventions that may affect population health and health equity. Such interventions are strongly influenced by context - taken to refer to any feature of the circumstances in which an intervention 
is conceived, developed, implemented and evaluated. Understanding how interventions relate to context is critical to understanding how they work; why they sometimes fail; whether they can be successfully adapted, scaled up or translated from one context to another; why their impacts vary; and how far effects observed in one context can be generalised to others.

Concerns that context has been neglected in research to develop and evaluate population health interventions have been expressed for at least 20 years. Over this period, an increasingly comprehensive body of guidance has been developed to help with the design, conduct, reporting and appraisal of PHIR. References to context have become more frequent in recent years, as interest has grown in complex and upstream interventions, systems thinking and realist approaches to evaluation, but there remains a lack of systematic guidance for producers, users and funders of PHIR on how context should be taken into account.

This document draws together recent thinking and practical experience of addressing context within PHIR. It provides a broad, working definition of context and explains why and how context is important to PHIR. It identifies the dimensions of context that are likely to shape how interventions are conceptualised, the impacts that they have and how they can be implemented, translated and scaled up. It suggests how context should be taken into account throughout the PHIR process, from priority setting and intervention development to the design and conduct of evaluations and reporting, synthesis and knowledge exchange. It concludes by summarising the key messages for producers, users and funders of PHIR and suggesting priorities for future research. The document is meant to be used alongside existing guidance for the development, evaluation and reporting of population health interventions. We expect the guidance to evolve over time, as practice changes in the light of the guidance and experience accumulates on useful approaches.

The work was funded by the Canadian Institutes of Health Research (www.cihr-irsc.gc.ca) - Institute of Population and Public Health (CIHR-IPPH) and the UK National Institute for Health Research (NIHR). 


\section{Contents}

List of tables

List of figures xiii

List of boxes $\quad$ xV

List of abbreviations $\quad$ xvii

Chapter 1 Introduction 1

Why do we need a focus on context and what do we aim to achieve? 1

Origins and development of the guidance 3

Key terms 3

Chapter 2 Conceptual issues: what do we mean by 'context' and how do we identify its relevant features?

What do we mean by 'context'?

Identifying the relevant features of context for a population health intervention research study 6

Recommendations 8

Chapter $\mathbf{3}$ Taking account of context in the population health intervention

research process 9

Defining the public health problem and associated research questions 9

Recommendations 12

Developing and adapting interventions 12

$\begin{array}{ll}\text { Recommendations } & 16\end{array}$

$\begin{array}{ll}\text { Evaluating interventions } & 16\end{array}$

$\begin{array}{ll}\text { Realist approaches } & 17\end{array}$

$\begin{array}{ll}\text { Process evaluation } & 17\end{array}$

$\begin{array}{ll}\text { Causal modelling } & 19\end{array}$

$\begin{array}{lr}\text { Recommendations } & 20\end{array}$

Reporting, synthesis and knowledge exchange 20

$\begin{array}{ll}\text { Reporting } & 20\end{array}$

$\begin{array}{ll}\text { Evidence synthesis and knowledge exchange } & 21\end{array}$

Recommendations $\quad 22$

Chapter 4 Conclusion and recommendations $\quad 25$

$\begin{array}{ll}\text { Chapter } 5 \text { Case studies } & \mathbf{2 7}\end{array}$

Stage 1: defining the public health problem and associated research questions 27

Case study 1: Visioning Health II - indigenous, participatory evaluation and

assessment of a culturally grounded and arts-informed intervention for human

immunodeficiency virus-positive indigenous women $\quad 27$

Case study 2: preventing exposure of children to foods high in fat, salt and sugar -

evaluation of the Office for Communications Regulation regulation of

television advertising 
Case study 3: establishing leadership hubs to improve nursing care for human immunodeficiency virus/acquired immune deficiency syndrome patients in four low- and middle-income countries - understanding system and organisational dimensions of context

Stage 2: developing and adapting interventions

Case study 4: AmaQhawe - a community empowerment approach to adapting a complex intervention

Case study 5: babyClear - an intervention to prevent smoking in pregnancy 30

Case study 6: Football Fans in Training 31

Stage 3: evaluating interventions

Case study 7: A Stop Smoking in Schools Trial - a peer-led smoking prevention intervention for use with students in secondary schools

Case study 8: a national subsidy policy for birth deliveries in Burkina Faso

Case study 9: the iConnect and Commuting and Health in Cambridge studies of new transport infrastructure

Stage 4: reporting, synthesis and knowledge exchange

Case study 10: a Cochrane systematic review of the World Health Organization

health-promoting school framework

\section{Acknowledgements}

\section{References}




\section{List of tables}

TABLE 1 Features of context: a synthesis with examples

TABLE 2 Stages of the research process at which context needs to be taken into account 



\section{List of figures}

FIGURE 1 (a) Initial and (b) revised ToC for the Scottish government's alcohol strategy

FIGURE 2 Key functions of process evaluation: MRC guidance 



\section{List of boxes}

BOX 1 Population health interventions and PHIR

BOX 2 Definitions of context: examples

BOX 3 Social theory and PHIR

10

BOX 4 Ethnic and cultural context: research with indigenous communities 



\section{List of abbreviations}

\begin{tabular}{|c|c|c|c|}
\hline AIDS & acquired immune deficiency & LMIC & low- and middle-income country \\
\hline & syndrome & MRC & Medical Research Council \\
\hline ASSIST & A Stop Smoking in Schools Trial & $\mathrm{NIHR}$ & National Institute for Health \\
\hline BMI & body mass index & & Research \\
\hline CHAMP & $\begin{array}{l}\text { Collaborative HIVIAIDS Adolescent } \\
\text { Mental Health Programme }\end{array}$ & Ofcom & $\begin{array}{l}\text { Office for Communications } \\
\text { Regulation }\end{array}$ \\
\hline \multirow[t]{2}{*}{ CIHR-IPPH } & \multirow{2}{*}{$\begin{array}{l}\text { Canadian Institutes of Health } \\
\text { Research - Institute of Population } \\
\text { and Public Health }\end{array}$} & PHIR & $\begin{array}{l}\text { population health intervention } \\
\text { research }\end{array}$ \\
\hline & & PHR & Public Health Research \\
\hline $\mathrm{CMO}$ & context-mechanism-outcome & ToC & \\
\hline CONSORT & $\begin{array}{l}\text { Consolidated Standards of } \\
\text { Reporting Trials }\end{array}$ & VHI & Visioning Health I \\
\hline FFiT & Football Fans in Training & VHII & Visioning Health II \\
\hline FNP & Family Nurse Partnership & WHO & World Health Organization \\
\hline HIV & human immunodeficiency virus & & \\
\hline
\end{tabular}





\section{Chapter 1 Introduction}

\section{Why do we need a focus on context and what do we aim to achieve?}

Population health intervention research (PHIR) develops and evaluates policies, programmes and other interventions that seek to have an impact on population health and/or health equity by modifying the underlying determinants of health or by directly influencing health behaviours. Such interventions are sensitive to context, by which we mean any feature of the circumstances in which an intervention is conceived, developed, implemented and evaluated (see Chapter 2). Many population health interventions work to change the context within which health is produced and become part of the context for future health behaviours, interventions and outcomes. Understanding the relationship between interventions and contexts is critical to understanding implementation success and failure, how interventions achieve impact, why their impacts vary and whether interventions can be sustained or successfully translated from one context to another.

Concerns that too little emphasis is placed on the relationships between interventions and contexts have been expressed for at least 20 years. Pawson and Tilley ${ }^{1}$ identified lack of attention to context as a critical weakness of prevailing approaches to evaluation and a key motivation for developing an alternative 'realist' approach. Also writing in 1997, Birch ${ }^{2}$ drew attention to the risk that the developing field of evidence-based medicine encouraged a focus on unbiased estimates of average treatment effects, at the expense of understanding how effects vary by population and health-care system characteristics. A 2002 review found that none of the 'checklists in common use to assess the quality of evidence for a public health intervention contain details on how the differential effect of context (however defined) could be taken into account'. ${ }^{3}$ Other reviews of both substantive intervention studies and frameworks for interpreting public health evidence reached similar conclusions. ${ }^{4,5}$

Since then, an increasingly comprehensive body of guidance has been developed to help with the design, conduct, reporting and appraisal of PHIR and references to context have become more frequent. This increase has had a number of drivers. One is methodological interest in evaluation approaches that go beyond the identification of average treatment effects, including systems thinking, ${ }^{6}$ process evaluation, ${ }^{7}$ causal modelling ${ }^{8}$ and implementation research..$^{9-11}$ Another is substantive concern with health inequalities and the possibility that effective interventions (in the sense that they improve population health overall) may fail to reduce or may even widen health inequalities. ${ }^{12-14} \mathrm{~A}$ third is the failure to replicate initial trial findings when interventions are implemented more widely. ${ }^{15,16} \mathrm{~A}$ fourth is social theorists' critique of research that uses abstract representations of health risks and interventions that are not situated in time, place and social, cultural, political, economic and other circumstances. ${ }^{17}$

Recognition of the importance of context in principle has not yet been translated into widespread good practice. There have been a number of useful recent contributions to clarifying terminology and concepts, ${ }^{18,19}$ but there remains a lack of systematic guidance for producers, users and funders of PHIR evidence on how context should be taken into account. A 2015 review of intervention studies published in 10 leading public health journals found that, with a few exceptions, treatment of context was superficial, with cursory descriptions of a narrow range of contextual factors, largely treated as confounders or as obstacles to intervention delivery or fidelity. ${ }^{20}$ Another study published in 2017 found that references to social context had become less frequent in health behaviour change intervention research since 2006 and called on research funders and other stakeholders to develop guidance on how to take account of social and cultural contexts. ${ }^{18,21}$ 
There is a need both to identify existing good practice and to move the field forward by extending existing perspectives and inviting new approaches that address the significance of context for population health interventions. This document seeks to pull together recent thinking and practical experience of addressing context within PHIR. Its intended audiences include:

- established PHIR researchers as well as researchers new to the field, from all disciplines with an interest in contributing to PHIR and teaching

- research funders and journal editors, who play a role in setting agendas, priorities and structures for how PHIR is conducted, peer reviewed and reported

- peer reviewers of research funding applications and journal manuscripts, who shape what research is funded and disseminated and what capacity is built among those working in the field

- users of PHIR, who need to infer from the evidence whether or not an intervention is applicable to their own context and what impacts they can expect were they to implement the intervention in its original or in an adapted form.

Recent efforts to build and strengthen the field of PHIR have placed greater emphasis on context. This document builds on such work. Its basic premise is that, rather than treating context as a source of 'noise' or a barrier to implementation, understanding the relationships between interventions and their contexts is vital to determining how interventions work (or why they fail) and their applicability to different settings and populations. Our primary focus is on research that seeks to improve population health and reduce health inequalities through interventions that act on the underlying determinants of health or more directly on health behaviours, ${ }^{22,23}$ but the issues are also relevant across the whole range of public health and health services research.

Taking context more fully into account in PHIR (and related fields) will improve the quality and usefulness of research evidence in four important and closely related ways. First, taking account of context in the development of interventions should lead to more appropriate, implementable, effective and sustainable interventions that either work well in a specific context or have sufficient flexibility built in to their design to work across a range of contexts. Second, understanding how interventions relate to context is key to understanding how they work. Failure to take account of such relationships is one reason why interventions shown to be effective in one setting fail to achieve similar impacts elsewhere, even if they are replicated faithfully and implemented successfully in the new setting. Third, understanding the relationship between intervention and context helps to explain why impacts vary and, in particular, whether an intervention is likely to narrow or widen inequalities in health, for example by ethnicity, gender or socioeconomic status. Finally, including adequately detailed accounts of context in reports of intervention studies will make them more useful to decision-makers interested in implementing, adapting, sustaining, transferring and scaling up interventions and to researchers developing theoretical models of change underlying improvements in public health.

In the following sections, we explain the origins of the guidance and the writing process and define some key terms. In Chapter 2, we provide a broad, working definition of context. We identify the features of context that are likely to interact with interventions in ways that cause variation in impact and help or hinder implementation, translation and scaling up. In Chapter 3, we outline how context should be taken into account throughout the PHIR process, from priority setting (see Defining the public health problem and associated research questions) and intervention development (see Developing and adapting interventions) to the design and conduct of evaluations (see Evaluating interventions) and to reporting, synthesis and knowledge exchange (see Reporting, synthesis and knowledge exchange). In Chapter 4, we summarise the key messages for producers, users and funders of PHIR and suggest priorities for future research. Chapter 5 contains summaries of the case studies that we draw on throughout the document. 


\section{Origins and development of the guidance}

Development of the guidance was initiated by the Canadian Institutes of Health Research - Institute of Population and Public Health (CIHR-IPPH) and the UK National Institute for Health Research (NIHR) Public Health Research (PHR) programme, two national research funding agencies that share an interest in advancing the evidence base for population health interventions. In 2014, the agencies commissioned two background papers that explored current understanding and use of context(s) in PHIR: one by Shoveller and colleagues ${ }^{20}$ and one unpublished [Petticrew M, Moore L. What is this Thing Called Context (and Why Does it Matter for Evaluation)? London School of Hygiene \& Tropical Medicine; 2015]. The papers identified a range of ways in which the treatment of context could be improved and a lack of systematic guidance within existing documents. In response, the agencies convened a workshop in London, UK, in November 2015, involving 16 experienced population health researchers from a variety of disciplinary backgrounds. The face-to-face workshop provided a forum to:

- discuss and debate pitches and provocations about the relationships between context and population health interventions (implementation and outcomes) to identify key issues to be addressed in guidance

- decide how best to build on and extend foundations provided by existing background papers and interest in developing guidance

- scope an outline for what the guidance should look like and determine roles, responsibilities and timelines for its production and dissemination.

Following the workshop a smaller editorial group convened to draft a guidance document for discussion at a second workshop in Ottawa, ON, Canada, in April 2016. The draft was then revised iteratively, first within the editorial group and then including comments from workshop participants and five independent reviewers.

\section{Key terms}

Population health interventions aim to improve health and reduce inequalities in health. They seek to reduce population health risk by changing underlying social, cultural, economic or environmental conditions ${ }^{22}$ or by acting directly on health behaviours. ${ }^{24}$ These interventions may involve one or more modalities and components and may be designed and developed in any sector of economic and social policy, including fiscal policy, urban planning, education, housing and employment, as well as health. PHIR uses a wide variety of quantitative and qualitative research designs and methods to identify, understand and measure the effects of these interventions, the processes by which they bring about change and the contexts in which they work best. Box 1 explains in more detail how we have defined PHIR for the purposes of this guidance document.

Population health intervention research is a multidisciplinary effort and 'context' is one of a number of key terms that may mean different things to different sectors of the PHIR and wider research community. We discuss the varying meanings of the term 'context' in Chapter 2 and explain why we have adopted a broad definition that encompasses any feature of the circumstances in which an intervention takes place that is relevant to understanding how it is implemented, how it effects change or how it is responded to or engaged with. Understood in this way, context incorporates the commonly used term 'setting', but covers a broader range of dimensions. When terms have been defined in conflicting or overlapping ways in the literature, such as 'transferability', 'applicability' and 'generalisability', we define the sense that we are adopting the first time that we use the term. Other terms, such as 'interaction', which have both a specific or technical meaning (as in statistical interaction) and a broader meaning (e.g. social interaction), are used in the broader sense unless otherwise specified. 
Population health interventions form a spectrum, from policy interventions delivered to a whole population irrespective of baseline risk, such as legislative smoking bans, to those targeted at subpopulations with raised levels of risk, but delivered at a scale sufficient to change the population distribution of risk. Population health strategies may combine high-risk and whole-population approaches. An example of such a combined approach might be a national alcohol strategy that included action on the price and availability of alcohol, alongside measures to improve access to brief interventions for harmful drinkers. This guidance document draws on examples of both kinds of interventions and is intended to inform future research across the whole spectrum. We also consider all stages of the research process, from intervention development through to reporting and evidence synthesis, and draw on examples of a range of evaluation designs, from randomised trials to natural experiments. Although context has often been ignored or downplayed in trials-based research, interest is growing in ways of adapting trial designs to take better account of context. At the same time, an acknowledgement that many population health interventions cannot be evaluated using randomised trials has led to increasing interest in the use of natural experiments. So far, the focus of methodological work on natural experiments has been on ways of strengthening causal inference and optimising 'internal validity'. As with trials, it is equally important to consider external validity - the applicability of evidence to particular contexts - in the design of natural experimental studies. This guidance document is intended to inform the design of evaluation studies in either tradition, with the primary focus on PHIR. 


\section{Chapter 2 Conceptual issues: what do we mean by 'context' and how do we identify its relevant features?}

\section{What do we mean by 'context'?}

Existing definitions of context in PHIR and related literatures differ in detail, but share a number of key features (Box 2). First, they emphasise that population health interventions are social practices, created, delivered, adapted and experienced by people who influence, and who are influenced by, the social, cultural, political and economic circumstances in which they live. Second, they recognise that the features

\section{BOX 2 Definitions of context: examples}

Context refers to the social, political and/or organisational setting in which an intervention was evaluated, or in which it is to be implemented. The contextual characteristics that are relevant vary with the type of intervention.

\section{Rychetnik et al. ${ }^{3}$}

The local mix of conditions and events ... which characterise open systems ... whose unique confluence in time and space selectively activates... causal powers ... in a chain of reactions that may result in very different outcomes depending on the dynamic interplay of conditions and mechanisms over time and space.

Context consists of a constellation of active interacting variables and is not just a backdrop for implementation. For implementation research, 'context' is the set of circumstances or unique factors that surround a particular implementation effort. ... [W]e use the term context to connote this broad scope of circumstances and characteristics.

Damschroder et al. ${ }^{9}$

By context we refer very broadly to a range of factors such as the study setting, existing health or other systems, payment mechanisms, available resources, social norms, community supports, relationships between different actors, political context, and many others, which can all have a critical impact on applicability.

Burford et al. ${ }^{25}$

Context refers to the broad setting in which trials occur, including socio-economic characteristics, culture, geography, legal environment, and service structures.

Context includes anything external to the intervention that may act as a barrier or facilitator to its implementation, or its effects.... Understanding context is therefore critical in interpreting the findings of a specific evaluation and generalising beyond it. Even where an intervention itself is relatively simple, its interaction with its context may still be highly complex.

Context is conceptualized as a set of characteristics and circumstances that consist of active and unique factors that surround the implementation. As such it is not a backdrop for implementation but interacts, influences, modifies and facilitates or constrains the intervention and its implementation. 
of context that need to be taken into account are intervention specific: not every aspect of context is relevant in every case. Third, they emphasise the importance of interactions between interventions and context in understanding both causal mechanisms and variation in effects. Fourth, they define context broadly, to include characteristics that vary between individuals in a population (such as income or ethnicity) and features of the environment that affect the whole population (such as water quality or the health-care system). Finally, they assume a distinction between intervention and context, although, as we have noted, many population health interventions are intended to modify contexts and thereby become part of the context in which health is produced in future. We acknowledge that a complete understanding of the relationships between intervention and context may require interventions to be conceived as 'events in systems', ${ }^{6}$ although implementing such a research paradigm is demanding ${ }^{27,28}$ and useful insights may be gained from approaches with a more specific focus on particular dimensions of context.

We support a broad understanding of context, to include (1) factors sometimes categorised separately as contextual (applying to a whole population) compared with compositional (varying between individuals within a population); (2) features of the physical location or geographical setting of interventions, as well as cultural, social, economic and political aspects; and (3) factors affecting implementation (organisation, funding, policy, etc.), as well as those directly affecting outcomes. Accordingly, we use context to refer to any feature of the circumstances in which an intervention is implemented that may interact with the intervention to produce variation in outcomes. These features may include, but are not limited to, the following domains: co-interventions or 'treatment as usual'; the immediate and wider organisational setting of the intervention; geographical environment, both physical and human; demographic, epidemiological and socioeconomic characteristics of those delivering the intervention and the recipient population; cultural practices, beliefs and attitudes among those delivering the intervention and the recipient population; legal and ethical rules and conventions; broader policies within which the intervention is embedded; historical and political factors that affect the acceptability of the intervention; 29 and how or whether or not the targeted population engages with the intervention.

\section{Identifying the relevant features of context for a population health intervention research study}

Deciding how to conceptualise context, and which features of context should be addressed in a particular intervention study, should be seen as significant research tasks in their own right. A number of frameworks have been suggested to help researchers pose the relevant questions. Poland and colleagues ${ }^{30}$ provide a framework for use with health-promotion interventions. This framework comprises 20 questions that can be used to identify salient features of context, organised into five categories: (1) diversity across and within categories of settings; (2) received knowledge; (3) localised determinants of health; (4) stakeholders and interests; and (5) power, influence and social change. The framework is designed to be used collaboratively, to improve stakeholders' as well as researchers' understanding of the context within which an intervention takes place. Importantly, it recognises the need to take account of the history of an intervention in a particular setting and the differing interests of groups of stakeholders.

Another potentially useful guide is the Consolidated Framework for Implementation Research,, 931 which includes an 'inner setting' containing six constructs relating to characteristics of the implementing organisation and an 'outer setting' containing four constructs related to the organisation's operating environment, as part of a broader set of constructs for use in implementation research. Vanderkruik and McPherson ${ }^{32}$ set out a contextual factors framework for public health that comprises four primary levels [(1) external environment, (2) organisation, (3) initiative (i.e. intervention) and (4) site/local team], each divided into a number of secondary levels, which in turn comprise a bundle of specific components. The Context and Implementation of Complex Interventions $(\mathrm{CICl})$ framework ${ }^{18}$ for taking context into account in health technology assessments and systematic reviews sets out a relatively comprehensive range of 
domains of context (geographical, political, epidemiological, etc.) and suggests that for each domain researchers should ask:

- Which [domain] characteristics influence the intervention, its implementation, its population reach and its effectiveness?

- How do [domain] characteristics exert their influence on the intervention, its implementation and its outcomes?

- How do [domain] characteristics interact with other domains of context?

Although useful, none of the existing frameworks or typologies for characterising context is entirely satisfactory for the study of complex population health interventions. They have been developed for differing purposes (health promotion, health technology assessment, implementation research, evidence synthesis, etc.) and vary widely in the way that they distinguish between intervention and context, what dimensions are included, how the dimensions are defined and the weight given to each. Table 1 seeks to combine and consolidate the dimensions identified in these frameworks into a more comprehensive list of categories for PHIR purposes.

\section{TABLE 1 Features of context: a synthesis with examples}

\begin{tabular}{|c|c|c|}
\hline Feature & Description & $\begin{array}{l}\text { How the dimension may interact with an } \\
\text { intervention to influence implementation } \\
\text { and/or outcomes: examples }\end{array}$ \\
\hline
\end{tabular}

Epidemiological Baseline incidence, prevalence and distribution of the health problem of interest and its determinants in the target population

Social and economic Distribution of social and economic resources among communities or populations affected by the intervention

Cultural

Geographical/ environmental

Service and organisational
Beliefs, attitudes and practices among policy-makers, practitioners and those targeted by the intervention

Features of the immediate or more distal (e.g. regional or national) physical environment, either natural or built

Characteristics, such as readiness to change and motivation, of the individuals delivering the intervention, the organisations in which they work and the wider service environment in which those organisations operate

Co-interventions that target the same risk factors, behaviours or outcomes within the same population as the intervention of interest
Effect sizes will vary according to base rates and underlying trends in the outcomes of interest

Communities or individuals within the target population may lack the resources to respond to the intervention, be deterred by co-payments or other costs associated with participation or be reluctant to change practices from which they derive an immediate economic benefit

Practitioners may be reluctant to implement interventions that call into question traditional beliefs; uptake of an intervention may be encouraged by strong alignment with cultural norms

Costs of delivering, scaling up or accessing an intervention may be higher in a more dispersed population; existing urban form may limit or potentiate the impact of new infrastructure

A tradition of quality improvement or strong leadership within a delivery organisation, or commitment to the particular issue, may encourage innovation and implementation; alternatively, weak leadership, a lack of engagement or pressures on existing services may constrain the impact of a novel intervention

The effects of a new intervention may be smaller when 'treatment as usual' is of relatively high quality or greater if complementary services are available; a novel intervention may be more risky if related services are poorly developed; effectiveness of preventative interventions may decline if new treatments become available that change perceptions of risk 
TABLE 1 Features of context: a synthesis with examples (continued)

\begin{tabular}{|c|c|c|}
\hline Feature & Description & $\begin{array}{l}\text { How the dimension may interact with an } \\
\text { intervention to influence implementation } \\
\text { and/or outcomes: examples }\end{array}$ \\
\hline Ethical & $\begin{array}{l}\text { The extent to which implementers and } \\
\text { recipients are in equipoise about the benefits } \\
\text { and harms of the intervention and are able to } \\
\text { provide informed consent to exposure to the } \\
\text { intervention and participation in associated } \\
\text { research }\end{array}$ & $\begin{array}{l}\text { Strongly held beliefs about the benefits or } \\
\text { harms of an intervention may deter stakeholders } \\
\text { from supporting an experimental evaluation or } \\
\text { individuals from participating in one }\end{array}$ \\
\hline Policy & $\begin{array}{l}\text { The wider policy framework within which a } \\
\text { specific intervention is embedded }\end{array}$ & $\begin{array}{l}\text { Effects may be greater if the intervention } \\
\text { interacts positively with other components of a } \\
\text { broader set of policies }\end{array}$ \\
\hline Legal & $\begin{array}{l}\text { Legal rules, regulations and mandates that } \\
\text { constrain or enable implementation of } \\
\text { the intervention }\end{array}$ & $\begin{array}{l}\text { Supranational judicial or regulatory processes } \\
\text { may prevent or delay implementation of } \\
\text { national policies }\end{array}$ \\
\hline Financial & $\begin{array}{l}\text { Sources and mechanisms of funding for the } \\
\text { intervention and the wider payment, reward, } \\
\text { incentive or charging structures in which they } \\
\text { are embedded }\end{array}$ & $\begin{array}{l}\text { Distribution of costs and benefits may not be } \\
\text { aligned: costs and benefits may fall in different } \\
\text { sectors [e.g. local government (prevention) } \\
\text { vs. health sector (reductions in morbidity)]; } \\
\text { cost-saving interventions may be unsustainable } \\
\text { unless the savings can be recouped by the } \\
\text { implementing organisation }\end{array}$ \\
\hline Political & $\begin{array}{l}\text { Distribution of power among stakeholders } \\
\text { and others with an interest in promoting } \\
\text { or obstructing the optimum design or } \\
\text { implementation of the intervention }\end{array}$ & $\begin{array}{l}\text { Influential stakeholders may obstruct effective } \\
\text { interventions that undermine existing power } \\
\text { relations/commercial interests or promote } \\
\text { less effective interventions that preserve } \\
\text { those advantages }\end{array}$ \\
\hline Historical & $\begin{array}{l}\text { Continuing influence of past conditions, } \\
\text { sociopolitical relationships, policies and } \\
\text { legal frameworks }\end{array}$ & $\begin{array}{l}\text { A tradition of community mobilisation may } \\
\text { encourage participation in community-led } \\
\text { interventions; alternatively, a history of } \\
\text { segregation may undermine the implementation } \\
\text { of interventions associated with a dominant } \\
\text { group or institution }\end{array}$ \\
\hline $\begin{array}{l}\text { External shocks and } \\
\text { catalytic events }\end{array}$ & $\begin{array}{l}\text { Extreme weather events, economic crises, } \\
\text { regime changes, onset of armed conflict, etc., } \\
\text { that affect implementation, sustainability or } \\
\text { uptake of the intervention or impact directly } \\
\text { on outcomes targeted by the interventions }\end{array}$ & $\begin{array}{l}\text { Adverse economic trends that reduce the } \\
\text { affordability of health-damaging commodities } \\
\text { or change the social patterning of health } \\
\text { behaviours may confound the effects of an } \\
\text { intervention introduced at the same time }\end{array}$ \\
\hline
\end{tabular}

\section{Recommendations}

We recommend the use of the categorisation set out in Table 1, not as a checklist to apply in every study but as a set of prompts to the wide range of questions that need to be asked to identify the more salient features of context and to minimise the risk of overlooking potentially significant dimensions. Which dimensions are important in the study of a particular intervention will depend on the purpose of the research: a study that seeks to develop or evaluate the effectiveness of an intervention in a new context, or in a context that differs markedly from those in which previous evaluations have been conducted, may need to consider a wider range of dimensions than a replication study that takes place in a context that is similar to those in which previous evaluations have taken place. 


\section{Chapter 3 Taking account of context in the population health intervention research process}

ontext should be considered throughout the process of developing and evaluating population health interventions, from the initial definition of the public health problem onwards. For convenience, we divide the process into four stages (Table 2):

1. defining the problem and associated research questions

2. intervention development and adaptation

3. evaluation

4. reporting, evidence synthesis and knowledge exchange.

\section{Defining the public health problem and associated research questions}

How did context influence the way the public health problem was identified, defined and framed?

Whose priority is the intervention and whose interest(s) does it serve?

Whose priority is the evaluation and whose interests(s) does it serve?

TABLE 2 Stages of the research process at which context needs to be taken into account

Stage

Defining the public health problem and associated research questions

Developing and adapting interventions (or, for natural experiments, understanding how the intervention was developed)

Evaluating interventions

Reporting, synthesis and knowledge exchange

\section{Key questions}

How did context influence the way that the public health problem was recognised, defined and framed?

Whose priority is the intervention and whose interest(s) does it serve?

Whose priority is the evaluation and whose interests(s) does it serve?

In what contexts is the intervention expected to be applied?

In what ways are the causal mechanisms and modes of delivery context dependent?

Which dimensions of context are being taken into account and how are they being defined?

What evaluation methods and what theories are needed to take account of context?

How will the influence of context on effectiveness be assessed?

How does context constrain or enable implementation?

How has context shaped the findings and their interpretation?

How does the relationship between intervention and context reinforce or challenge existing theories of change?

What contexts are the findings applicable ${ }^{a}$ to and in what other contexts should future studies be conducted?

a Note that we use 'applicability' to refer to implementation of an intervention in a specific context, as distinct from 'generalisability', which refers to implementation across a wide range of contexts. Generalisability of population health interventions is limited by context dependencies, such that, even if it is feasible to implement an intervention widely, effects may vary substantially across different contexts.

( Queen's Printer and Controller of HMSO 2018. This work was produced by Craig et al. under the terms of a commissioning contract issued by the Secretary of State for Health and Social Care. This issue may be freely reproduced for the purposes of private research and study and extracts (or indeed, the full report) may be included in professional journals provided that suitable acknowledgement is made and the reproduction is not associated with any form of advertising. Applications for commercial reproduction should be addressed to: NIHR Journals Library, National Institute for Health Research, Evaluation, Trials and Studies Coordinating Centre, Alpha House, University of Southampton Science Park, Southampton SO16 7NS, UK. 
Although we are primarily concerned in this guidance with the context in which an intervention takes place, and the ways in which the relationship between intervention and context contributes to explaining outcomes, it is important to recognise that public health problems are framed within historical, cultural, political and economic contexts. ${ }^{29,33}$ In this section, we present examples to show that understanding the political context in which an intervention is developed, and in particular which stakeholders can exert influence, is important for defining realistic expectations about possible impacts and for designing evaluations that can go beyond routine monitoring or stakeholders' own evaluations. Understanding the wider social and political context of population health interventions is one area where PHIR can learn from social theory ${ }^{34}$ (Box 3).

Much PHIR is policy driven in the sense that policy-makers identify and prioritise particular problems that then become the focus of research. Often, policy change creates opportunities for evaluation that researchers must work out how to exploit, rather than basic science driving innovations that are then tested through a series of efficacy, effectiveness and implementation studies. The design and conduct of population health studies is dependent on relationships among research funders, researchers, policy-makers, intervention providers and recipients, who may hold differing views of the need for or purpose of an intervention or of the evaluation. The UK government's Responsibility Deal, ${ }^{44}$ launched in 2011, comprised a series of public-private partnerships, under which the commercial partners pledged to undertake voluntary actions to improve population health. The complexity of the scheme and weaknesses in the monitoring arrangements made evaluation difficult, but assessment of the pledges made by alcohol industry partners under the Deal

\section{BOX 3 Social theory and PHIR}

Population health intervention research can draw from contemporary developments in social theory that have a bearing on issues of context. Creating a deeper and more sustained relationship with social theory is one way for PHIR to strengthen its insights and build new directions for research. ${ }^{20}$ Two particular areas of social theory and research with potential to inform current debates in PHIR are (1) social problem theory and governmentality research and (2) the emerging field of relational sociology.

Social problems theory was popularised by American sociologists in the 1970s in research exploring how drinking, smoking and other phenomena became recognised as social problems. ${ }^{35-38}$ Governmentality research derives from French social theorist and historian Michel Foucault's insights into shifts in modern forms of governance. ${ }^{39}$ Both fields offer insights that challenge taken-for-granted perspectives on how problems come to be identified. They direct attention to ways in which the activities and forms of knowledge used by researchers help to define a given phenomenon as a problem deserving of intervention. Social problems theory and governmentality research can heighten reflexivity within PHIR by calling attention to how population-level health problems are identified, by whom, through what processes and with what implications for the interventions that are designed to respond to them.

Relational sociology refers to a movement in social sciences that rejects the shared assumption of rational choice theory, structuralism and statistical variable analysis that entities 'come first and relations among them only subsequently'. ${ }^{40}$ Rather than conceiving of the social as pre-given static actors, substances or essences, relational sociologists emphasise that the social is always dynamic, unfolding, processual and networked. ${ }^{41}$ For example, Bilodeau and Potvin ${ }^{42}$ draw on actor-network theory to suggest a conceptualisation of public health interventions that emphasises how social and technical entities are linked in extended networks and how interventions and networks shape one another. Relational sociology offers insights from which to develop more complex, dynamic and networked understandings of interventions. Agent-based modelling, which involves 'simulation of large numbers of autonomous agents that interact with each other and with a simulated environment and the observation of emergent patterns from their interactions' has been advocated as one way in which theories about such dynamic relationships can be developed and tested. ${ }^{43}$ 
showed that the actions were not consistently underpinned by evidence and many commitments were to actions that were already being undertaken before the launch of the scheme. ${ }^{45-47}$

Understanding the historical context of a contemporary public health issue is particularly important in research involving indigenous peoples, recent migrants or minority cultures, who may have different views or understandings of what kinds of intervention are appropriate from those prevailing in the research community or among policy-makers (Box 4 and see Chapter 5, Case study 1).

The health behaviours, environments, organisational practices and policies targeted by population health interventions arise from social, cultural and political contexts. Even in a case such as smoking, for which the evidence of harms is unambiguous, and with a large proportion of smokers known to want to quit, taking full stock of the practices, policies, beliefs, norms, corporate influences and other factors that sustain smoking, and using theory to help understand how these elements are related, are essential to the identification of promising levers of change. Identifying who is in control of intervention development is key to understanding the eventual shape of an intervention, its potential impact on population health outcomes and the possibility of effective evaluation. In 2007, the UK government began to regulate the marketing to children of foods high in salt, fat and sugar by restricting the advertising of such foods during children's television programmes (see Chapter 5, Case study 2). The regulation was developed by the UK television advertising regulator [the Office for Communications Regulation (Ofcom)] in consultation with a range of parties including the food industry and advertising industry, followed by a public consultation on specific proposals. Research on the strategies used by stakeholders during the Ofcom consultations showed that food industry responses appeared to have influenced the regulations more strongly than those from public health interests (Rizavi S, Adams J, White M. Do Commercial, Consumer, Health or Civil Society Organisations Influence Public Health Policy and If So, How? Qualitative Study of Responses to The Ofcom Consultation on Regulation of TV Advertising to Children of Foods High in Fat, Salt and Sugar. MRC Epidemiology Unit, University of Cambridge; 2017). Ofcom's evaluation ${ }^{51}$ claimed success, but an independent evaluation showed that, although the regulation reduced the advertising of foods high in salt, fat and sugar during children's television programmes, overall exposure increased, notably during prime-time programmes, many of which are watched by children as well as adults. ${ }^{52}$

The importance of understanding the historical and political context in which interventions are developed and tested is also illustrated by the MINCOME guaranteed income experiment conducted in Manitoba from 1974 to 1978 , but not properly analysed until three decades later. Rising costs and a changing political

BOX 4 Ethnic and cultural context: research with indigenous communities

Relationships between ethnic and cultural groups are often strained by racism, ethnocentrism and the cultural oppression of some groups by others. These tensions shape the structural determinants of health (i.e. distribution of political, social and economic power and resources $)^{48}$ and influence virtually every human pursuit, including research. Without attention to cultural context, those who control the design and implementation of intervention research run the risk of failing to improve population health through interventions that are irrelevant, inaccessible or unachievable for a particular cultural group. Intervention researchers who are working across cultures must engage with participants on their own cultural terms, which means moving beyond superficial understandings of cultural diversity towards entrenching both research and intervention processes within specific cultural contexts. In some countries, a history of colonialism has created a legacy of distrust in political structures, including institutions of research. Previous attempts to strengthen research capacity in formerly colonial countries have often been tokenistic. ${ }^{49}$ Recent moves in Canada to ensure that indigenous communities have the right to control the process and products of research about, with and for them ${ }^{50}$ are beginning to establish trust between researchers and indigenous peoples, but it will take time and effort to fully develop the necessary relationships, processes and research capacity for formerly disempowered peoples to conduct research, rather than being the subject of studies conducted by dominant groups. 
climate led to the premature restriction of the original wide-ranging research programme and the eventual closure of the experiment. The initial motivation for MINCOME, and for the earlier negative income tax experiments in the USA, was to test the effects of improving income security on labour supply. Interest in health inequalities grew over the next 30 years and later researchers were able to exploit improvements in data infrastructure to explore a wider range of social and health impacts by matching MINCOME participants with control participants from elsewhere in rural Manitoba. The research found a substantial reduction in hospitalisations and in primary care consultations for mental health problems and a marked increase in the proportion of students continuing into grade 12 and graduating from high school. ${ }^{53,54}$

\section{Recommendations}

Why and how a public health issue has been defined as a problem, the need for and appropriateness of intervention and what counts as success may be perceived in markedly different ways by the populations affected, stakeholders with a commercial or a political interest, public health and other practitioners and the research community. Understanding the historical, political and cultural context in which decisions to intervene and evaluate are taken can help researchers to adopt approaches that are optimal for the circumstances in which the evaluation takes place.

\section{Developing and adapting interventions}

In what contexts is the intervention expected to be applied?

In what ways are the causal mechanisms and modes of delivery context dependent?

Which dimensions of context are being taken into account and how are they being defined?

Taking careful account of the context in which an intervention is to be applied is a prerequisite of good intervention design. The Six Steps for Quality Intervention Development (6SQuID) framework for intervention development encourages researchers to consider explicitly which contextual factors are modifiable, on the grounds that 'Most interventions take place within systems (e.g., healthcare, education, criminal justice) and exert their influence by changing relationships, displacing existing activities and redistributing and transforming resources'. ${ }^{55}$

Intervention developers should therefore think about how the intervention interacts with the system in which it is implemented and whether or not that system also needs to be modified.

To do this well requires a good practical as well as theoretical understanding of the context. Hawkins and colleagues ${ }^{56}$ set out a framework that emphasises the involvement of practitioners and other stakeholders in developing and prototyping interventions, to ensure that they can be adopted, implemented and maintained in the contexts for which they are intended. In developing an intervention to improve nursing care for patients with human immunodeficiency virus (HIV)/acquired immune deficiency syndrome (AIDS) in four low- and middle-income countries (LMICS), Edwards and colleagues ${ }^{57,58}$ identified the exclusion of nurses from guideline development and workplace policy-making processes as a reason for the weakness of such policies (see Chapter 5, Case study 3). They engaged nurses and those living with HIV/AIDS directly in the establishment of leadership hubs, where they worked alongside district decision-makers and other health professionals to improve clinical practices and workplaces for the care of patients with HIVIAIDS and their families.

Identifying prospectively all of the important contextual factors is likely to be difficult for novel interventions. Development of a 'theory of change' (ToC) that identifies the key dependencies between intervention and context may be helpful. ${ }^{59} \mathrm{ToC}$ is one of a number of closely related terms that are used more or less interchangeably in evaluation research to refer to a conceptual model of how an intervention is intended to 
achieve its impact. A ToC may draw on broader social or behavioural theories about how change occurs but is specific to the intervention being evaluated. De Silva and colleagues ${ }^{60}$ characterise a ToC as:

a theory of 'how and why an initiative works' which can be empirically tested by measuring indicators for every expected step on the hypothesized causal pathway to impact. It is developed in collaboration with stakeholders and modified throughout the intervention development and evaluation process.

It is useful to represent ToCs graphically, to clearly identify the causal pathways through which impacts are expected to occur.

A recent review of the use of ToCs in public health evaluation found only a few studies in which contextual factors had been incorporated as possible explanations of variation in intervention delivery or outcomes. ${ }^{61}$

To guide their 'theory-based evaluation' of the Scottish government's alcohol strategy, researchers at NHS Health Scotland developed a ToC that took into account components of the strategy and external factors affecting delivery and outcomes ${ }^{62}$ (Figure 1a). External factors addressed in the evaluation included income trends and deprivation patterns, the possible existence of a 'vulnerable cohort' in the Scottish population, reflecting earlier socioeconomic trends, previous alcohol policies, Scotland's drinking culture and the nature of the alcohol market.

A series of studies was undertaken to assess the impact of these factors, alongside studies of the impacts of components of the strategy, and the results were combined into a revised ToC (see Figure $1 \mathrm{~b}$ ).

Careful investigation of contextual factors is equally important when interventions developed and tested in one context are being adapted for use elsewhere. The Collaborative HIV/AIDS Adolescent Mental Health

(a)

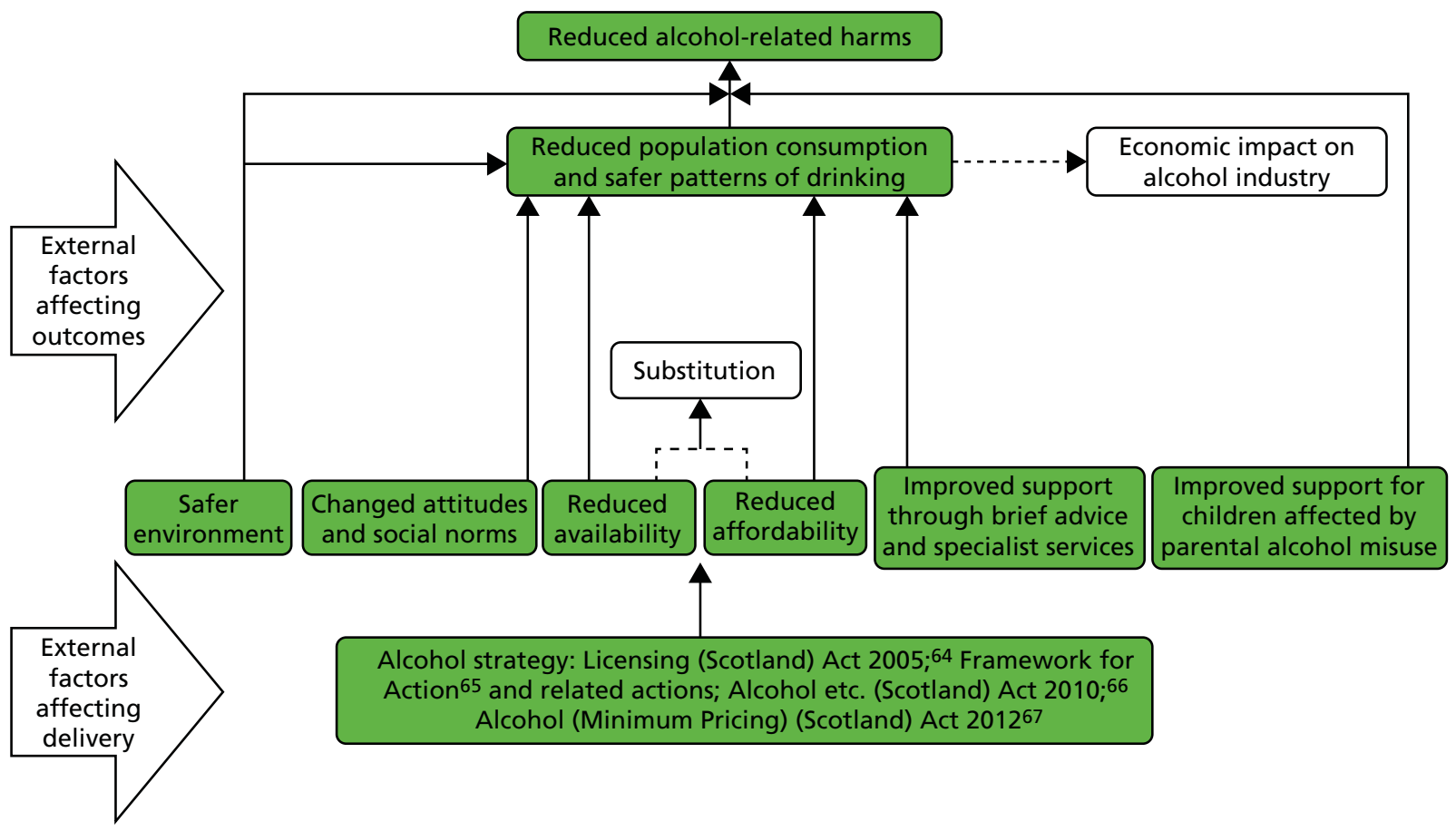

FIGURE 1 (a) Initial and (b) revised ToC for the Scottish government's alcohol strategy. ABI, alcohol brief intervention; LA, Licensing (Scotland) Act 2005;63 PSUR, ratio of prevalence of alcohol dependence to service users. Reproduced from Beeston and colleagues ${ }^{62}$ with permission of NHS Scotland. (continued) 
(b)

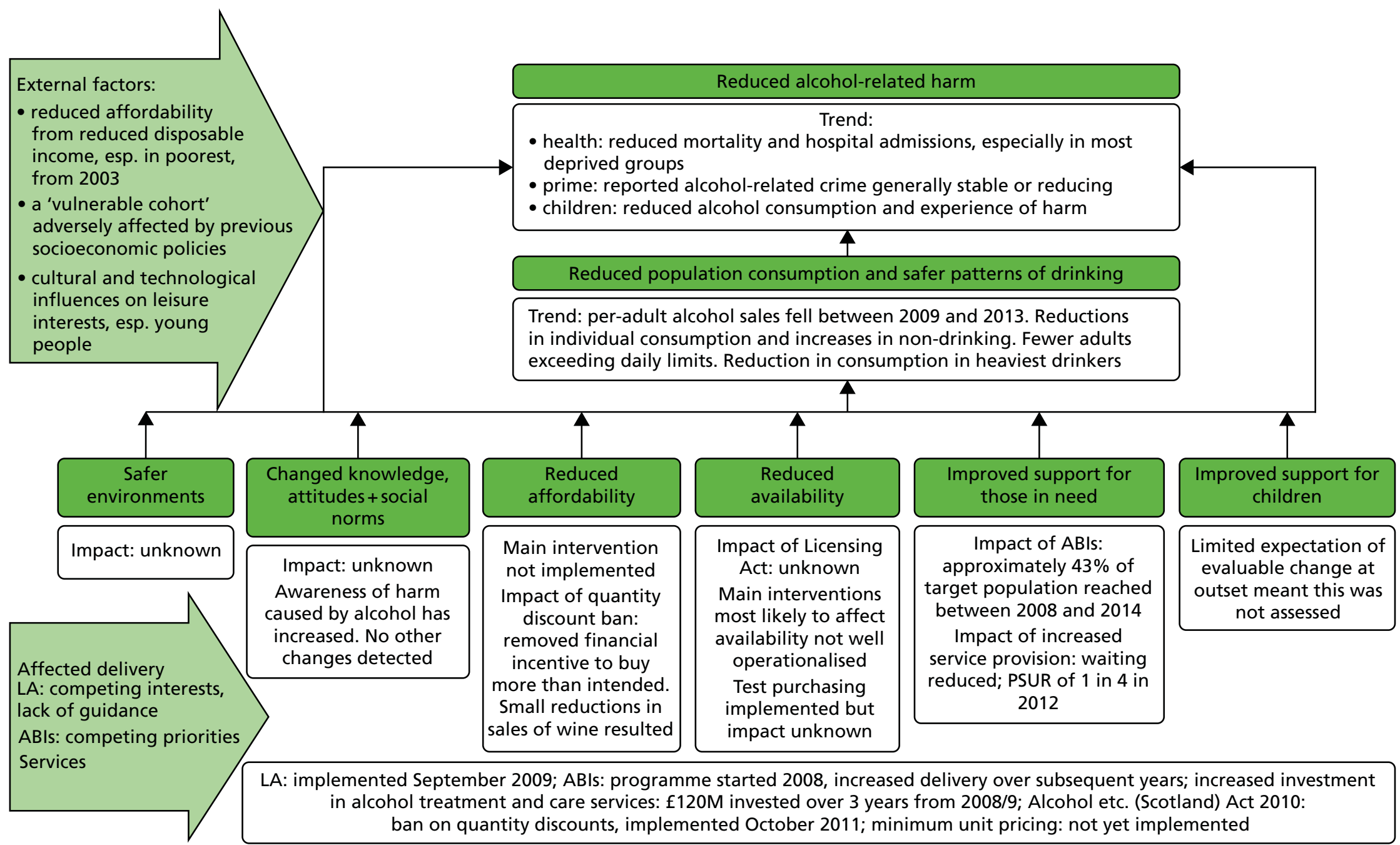

FIGURE 1 (a) Initial and (b) revised ToC for the Scottish government's alcohol strategy. ABI, alcohol brief intervention; LA, Licensing (Scotland) Act 2005; 63 PSUR, ratio of prevalence of alcohol dependence to service users. Reproduced from Beeston and colleagues ${ }^{62}$ with permission of NHS Scotland. 
Programme (CHAMP) was originally developed for African American populations and tested in Chicago. It was then adapted for use in South Africa as the AmaQhawe (Champions) programme (see Chapter 5 , Case study 4). ${ }^{67-69}$ A qualitative, ethnographic needs assessment identified features of the social, political and interpersonal contexts that were exacerbating the epidemic in South Africa: the apartheid legacy; patriarchal culture; macro-level sociocultural changes that threaten traditional parental roles, especially advocacy of children's rights; fractured leadership; children's schooling outstripping their parents' educational level; harsh parenting; poor parent-child communication; parental ignorance about HIV; and death of relatives. The AmaQhawe programme was adapted to take account of these factors by (1) incorporating sessions on stigma and bereavement; (2) adding a session on parent and child rights and responsibilities; (3) using cartoon narratives to address sexual topics that cultural taboos made sensitive to discuss; and (4) facilitating a more health-enhancing community context through building social competence and collective efficacy.

Likewise, to develop the babyClear intervention to prevent smoking in pregnancy (see Chapter 5, Case study 5), researchers wanted to understand why services that were effective in other populations were not working well for pregnant women. Accordingly, they focused on the interactions between pregnant smokers and midwives, rather than just on the choices made by the pregnant women. They found that midwives were reluctant to raise the issue of smoking for fear of damaging their relationship with their patients, ${ }^{70}$ so training for midwives and other staff was incorporated into a new care pathway. ${ }^{71}$

To develop the Football Fans in Training (FFiT) intervention (see Chapter 5, Case study 6), intended to help overweight men lose weight and adopt a healthier lifestyle, Hunt and colleagues ${ }^{72-74}$ drew on sociological theories of masculinity as well as on evidence for the design of behaviour change interventions. A key feature of FFiT was the use of a setting (professional football clubs in Scotland) that might attract and retain participants who would find traditional weight loss programmes unappealing. The gender-sensitised intervention successfully helped the men to lose weight and a process evaluation showed how the football clubs provided a physical, symbolic and social context in which the men felt comfortable addressing issues of weight loss and lifestyle change. The FFiT intervention is now routinely implemented in many professional football clubs across the UK and its potential for wider implementation is now being tested in a wide range of other sports and non-sport settings, countries and population groups.

In contrast, underestimation of the importance of context, or a failure to take account of all of the relevant contextual dimensions, can lead to difficulties with implementation or a lack of effectiveness, even if an intervention can be implemented successfully in a new context. The Nurse Family Partnership had been shown in a number of US trials ${ }^{75-77}$ and one European trial ${ }^{78}$ to be effective in improving a range of pregnancy, parenting, maternal health and social outcomes before it was implemented in the UK as the Family Nurse Partnership (FNP). A large well-conducted trial of FNP found that, despite successful implementation, there was no improvement across the four primary outcomes. ${ }^{79}$ The report concluded that benefits could not be assumed in 'different health-care settings and ... service populations, even when objective programme fidelity from US trials was maintained' ${ }^{79}$

An accompanying editorial suggested that the lack of any additional benefit associated with receipt of the FNP reflected the inclusion of all teenage mothers, rather than only the most disadvantaged, and the relatively high standard of usual care provided by the UK's comprehensive health visiting service. ${ }^{80}$ In this case, a concern with fidelity as the key to effectiveness appears to have overshadowed consideration of how impacts may vary according to features of context, such as population composition and the quality and intensity of treatment as usual, even though the heterogeneity of effects in the earlier trials suggested that factors other than programme fidelity were important sources of variation in effectiveness.

Understood as 'events in systems', ${ }^{6}$ interventions operate through complicated networks of causal pathways. Even when the importance of context is recognised, identifying and taking account of all of the relevant features of context is difficult. The MEMA kwa Vijana ('Good things for young people') programme, a multicomponent community-based intervention operating through schools and health 
facilities, was developed to reduce the incidence of sexually transmitted infections and unwanted pregnancy among young people in rural Tanzania. ${ }^{81} \mathrm{~A}$ process and outcome evaluation found improved sexual health knowledge, fewer reported sexual partners and more reported condom use, but no reduction in HIV or herpes infection or in pregnancy. ${ }^{82,83}$ The programme designers had tried to address important features of the local context, such as lack of electricity, long distances to understocked health centres, transactional sex, poor training of school teachers, health workers' judgemental attitudes towards adolescent sexual activity, cultural inhibitions about discussing sex, stigmatisation of condom use and opposition to condom education for school pupils. The failure of the programme can be interpreted partly as a consequence of an underestimation of the importance of the wider cultural, social and economic factors, such as women's dependence on men and on earnings from sex work, and partly as the consequences of poverty for the quality of schooling and understanding of reproductive biology.

Another example of the difficulty of anticipating all of the relevant features of context is the 'Lucky Iron Fish', a small fish-shaped iron ingot placed in a pot while cooking or boiling drinking water. Providing the ingots has been shown to be an effective way to reduce iron deficiency anaemia in women in some communities in rural Cambodia. ${ }^{84}$ The intervention was carefully developed to be effective and sustainable in this setting and population. The ingots could be produced locally, at lower cost than conventional nutritional supplements, and making them fish-shaped encouraged uptake because fish are considered lucky by Cambodian villagers. Even so, an earlier trial had found that short-term improvements in iron status were not sustained, because seasonal changes in water supply reduced the dietary availability of iron from the cooking water. ${ }^{85} \mathrm{~A}$ subsequent trial in a different region of Cambodia also found little benefit, because anaemia in this region was primarily due to inherited problems with haemoglobin production, rather than dietary iron deficiency. ${ }^{86}$

These examples illustrate both the importance of a good understanding of context for developing an effective intervention or adapting an existing intervention for a new context and the effort and skill required to address context adequately and identify all of its salient dimensions.

\section{Recommendations}

To guide the development and adaptation of interventions, researchers will find it helpful to draw on the relevant social and behavioural theory, and on stakeholders' practical experience, and to combine these in an intervention-specific ToC, identifying links between intervention components, context and outcomes. Representing the ToC diagrammatically, as a causal model or a system map, aids identification of the key dependencies, ${ }^{61}$ but some may become evident only in the course of evaluation, so researchers should update the theory in the light of pilot and effectiveness studies. Deciding which dimensions of context need to be included is an exercise in judgement, but any of the dimensions listed in Table 1 may be relevant. To adapt interventions to new contexts, it is useful to compare the old and the new contexts along those dimensions and to focus on those for which there is most discordance. Optimising an intervention known to be effective in one context for implementation in a closely related context may require attention only to features of the new setting or to the characteristics of a different recipient population. Developing a novel intervention, or adapting one for use in an entirely new context, will require attention to a much wider range of dimensions.

\section{Evaluating interventions}

What evaluation methods, theories and approaches are needed to take account of context?

How will the influence of context on effectiveness be assessed?

How does context constrain or enable implementation, reach, maintenance, transferability and scalability? 
Population health intervention research draws on the whole range of evaluation methods, from trials to natural experiments (see Box 1). No method is preferable in all cases. Approaches that seek to minimise bias and allow strong causal inference need to be complemented by methods to understand the processes involved and to determine how context specific or generalisable the findings are. Interest in context has been heightened by a number of recent methodological developments in the evaluation of population health interventions, as well as by engagement with social theories, such as those summarised in Box 3 . These methodological developments include realist approaches to evaluation, process evaluation and complex causal models linking context, mechanisms and outcomes. In Developing and adapting interventions, we addressed the issue of which aspects of context should be taken into account in the development and adaptation of interventions. Use of an explicit categorisation of context, coupled with a ToC that identifies the key contextual dependencies, is also critical to the evaluation of interventions. In this section we describe ways in which realist approaches, process evaluation and causal models can further help researchers evaluate contextual influences on the implementation and outcomes of population health interventions.

\section{Realist approaches}

Realist approaches to evaluation have focused attention on the importance of context for understanding effectiveness. In a realist framework, interventions are thought to achieve impact through context-mechanism-outcome (CMO) configurations: 'it is not programs that make things change, it is people, embedded in their context who, when exposed to programs, do something to activate given mechanisms, and change'. ${ }^{1}$

Although realist evaluation was originally characterised as an alternative to randomised trials, the principles are evident in many trials of complex public health interventions ${ }^{87}$ and 'realist trials' have recently been formally proposed as a way of combining the benefits of trials (minimisation of bias, relatively straightforward causal inference) and realist methods (understanding what works for whom, in what circumstances and why). ${ }^{88}$ Jamal and colleagues ${ }^{89}$ suggest that realist trials have three key stages. The first is to develop a ToC that identifies the CMO configurations through which the intervention is expected to achieve impact. The second is to conduct a qualitative process evaluation to refine the CMO hypotheses. The third is to test the hypotheses formally 'via quantitative analyses of effect mediation (to examine mechanisms) and moderation (to examine contextual contingencies)'. ${ }^{89}$

The goal of this approach is to investigate 'which interventions work best for which people and in which settings' ${ }^{89}$

To achieve the combination of unbiased estimates of impact and a detailed understanding of how and why impacts vary, Bonell and colleagues ${ }^{88}$ suggest that 'a more strategic, co-ordinated approach to testing the effects of interventions and their components in different contexts using consistent measures' is needed. They acknowledge that such co-ordination is rare and that a more 'joined-up' approach to research funding would be required to achieve it. In the meantime, there is a growing number of both trials and non-randomised evaluations that adopt elements of a realist approach, including paying careful attention to context.

\section{Process evaluation}

Whatever the evaluation design, identifying the important interactions between intervention and context requires a thorough process evaluation. Understanding context is central to the Medical Research Council's (MRC) guidance ${ }^{7}$ on process evaluation (Figure 2), which emphasises the importance of context to understanding the implementation process, mechanisms of impact and outcomes. That guidance emphasises the need to use a range of qualitative and quantitative methods to explore all of the relevant interactions, including documentary analysis, stakeholder interviews, qualitative observation and quantitative analysis of hypothesised moderators. The following two examples illustrate how process evaluation can help with the interpretation of effects identified in a trial or a natural experimental evaluation, by identifying features of context associated with variation in effectiveness or uptake of an intervention. 


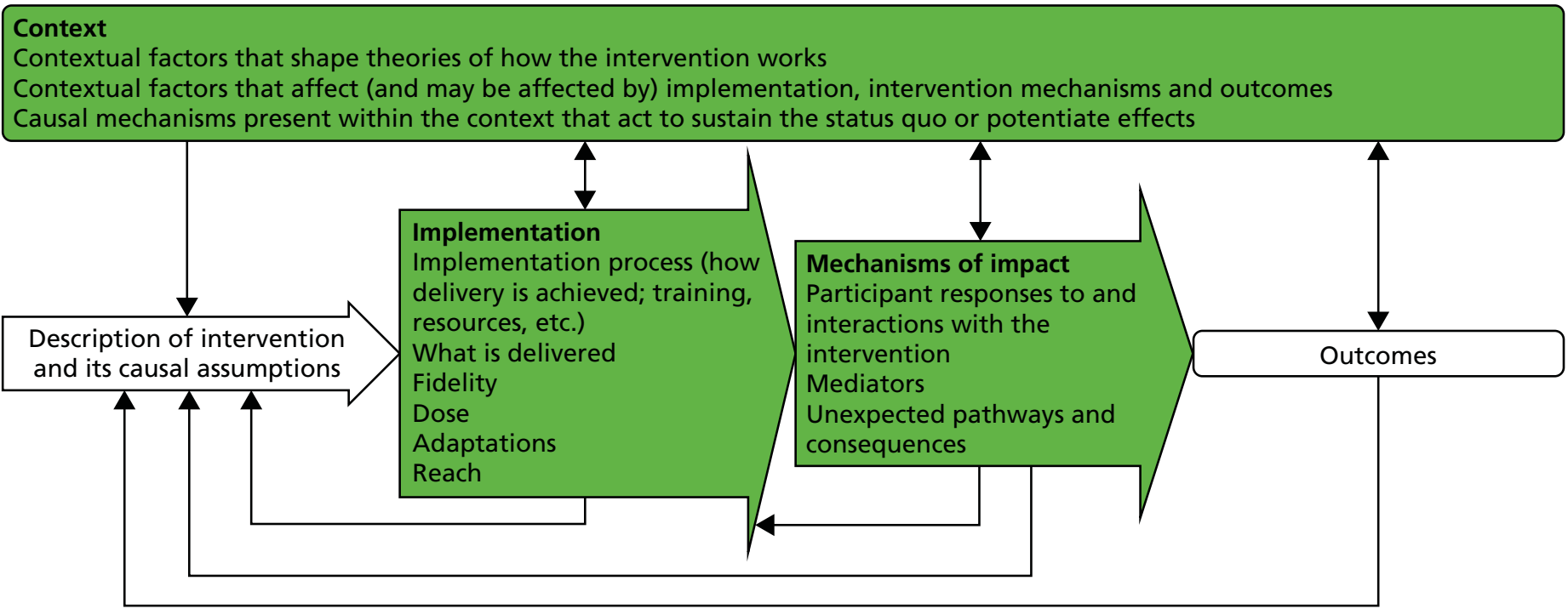

FIGURE 2 Key functions of process evaluation: MRC guidance. Reproduced from Moore and colleagues ${ }^{7}$ This is an Open Access article distributed in accordance with the terms of the Creative Commons Attribution (CC BY 4.0) license, which permits others to distribute, remix, adapt and build upon this work, for commercial use, provided the original work is properly cited. See: http://creativecommons.org/licenses/by/4.0/. 
Campbell and colleagues ${ }^{90}$ and Holliday and colleagues ${ }^{91}$ used an embedded process evaluation in their trial of a school-based, peer-led smoking prevention intervention (see Chapter 5, Case study 7) to understand how the intervention was perceived by stakeholders and the target population and whether or not and how context affected delivery. Consideration of context was used to develop the sampling and randomisation strategy, for example to include stratification by factors such as source of funding, size and geographical location, and also to prespecify subgroups for the quantitative analysis of outcomes. The trial showed that the intervention was effective across a wide range of schools but worked particularly well in communities that were served by a single secondary school.

Belaid and Ridde, ${ }^{92}$ De Allegri and colleagues ${ }^{93}$ and Ridde and colleagues ${ }^{94}$ (see Chapter 5, Case study 8) conducted a mixed-methods natural experimental evaluation of Burkina Faso's policy of subsidising the costs of giving birth in a health facility. Quantitative studies showed that the policy led to greater use of health facilities for deliveries and substantially reduced women's health expenditures, but there was wide variation in the extent and timing of improvement within and between districts and health centres. Mixed-methods research to identify contextual factors that could explain variation in uptake found that the quality of local leadership was important and that distance and household income remained significant barriers to the use of health facilities, thereby limiting the reach of the intervention, even when health-care costs were subsidised.

\section{Causal modelling}

Quantitative analysis of the way that contextual variables can moderate or mediate the effect of an exposure on an outcome is increasingly widely used in epidemiology and has begun to attract attention in PHIR. Contextual variables are typically moderators - variables that capture features of the context in which an intervention is implemented that may alter the magnitude or direction of its effects. In the causal chain linking an intervention with outcomes, they occur prior to exposure to the intervention. Mediators are variables that are intermediate between an exposure and an outcome that capture a hypothesised mechanism. However, interaction between the two may also be important: the effect of a mediator may vary according to the values of a moderating variable (moderated mediation) or the effect of a moderating variable may operate through a specific mechanism (mediated moderation). Context may, therefore, be implicated in both mediation and moderation of an intervention's effects.

In the iConnect ${ }^{95}$ and Commuting and Health in Cambridge ${ }^{96}$ studies of the impacts of new infrastructure for walking, cycling and public transport on travel and physical activity behaviour (see Chapter 5, Case study 9), Panter and colleagues ${ }^{96,97}$ and Prins and colleagues ${ }^{98}$ used path regression to identify which putative causal mechanisms triggered by the interventions were related to and interacted with their context. Rather than specifying and testing a single mediating relationship, the investigators hypothesised a more complex set of causal mechanisms, involving changes in perceptions of the physical and social environments and use of the new routes, as well as constructs of the theory of planned behaviour. They found that the majority of the behaviour change attributable to living closer to the interventions was mediated by use of the new routes rather than changes in cognitions or perceptions. ${ }^{97,98}$ These findings are consistent with a hypothesis that behaviour change can be promoted by altering environmental cues, without explicitly encouraging the target behaviours or directly addressing people's cognitions. As with all mediation analyses, however, the lack of evidence for certain hypothesised causal pathways could also reflect limitations in the sample size available for analysis and in the selection and measurement of the mediator variables.

Stratified path regression models were used to identify different causal pathways in groups of people with higher or lower levels of activity prior to the intervention. ${ }^{97}$ Analyses also showed how, in a particular context, an intervention could reduce the physical activity of some commuters by shortening the length of their cycle route to work or by increasing the attractiveness of the competing public transport service. ${ }^{98}$ In both studies, complementary qualitative and mixed-method analyses elicited plausible causal processes in which altering perceptions of the environment may have been important for triggering behaviour change in different groups and at different intervention sites. ${ }^{99,100}$ These findings helped explain some conflicting findings of the main outcome analyses and helped to interpret them for users in other contexts. 
The ability to quantify the role and mechanisms of action of contextual variables has obvious attractions for understanding how interventions achieve impact and why their impact varies between contexts. However, identifying mediation and moderation requires specialised statistical techniques. The validity of the findings depends on a correct specification of the underlying causal model and accurate measures of all of the relevant variables. These are challenging requirements and, to date, there are few applications of these techniques in PHIR and some controversy over the extent to which they mark a practical advance over more traditional methods. ${ }^{8,101}$ Causal inference in public health often entails making judgements about various assortments of 'ragged evidence' and it would therefore be unwise to rely entirely on a single, statistical method for inferring causal relationships. ${ }^{102}$

\section{Recommendations}

In Developing and adapting interventions, we stressed the importance of explicitly considering the key conceptual dependencies at the intervention development stage. Use of a formal categorisation such as that in Table 1 may also be helpful in deciding which features of context an effectiveness study should address. For natural experimental studies, in which intervention development is out of the hands of researchers, it may still be useful to go through the process of considering these dependencies and setting them out in an explicit ToC. Whatever the evaluation design, researchers should be prepared to revise their ToC in the light of study findings, as recommended in Developing and adapting interventions. Although randomised trials conducted within a particular context, by their nature, control for features of that context, realist approaches suggest a number of ways in which context can be taken into account in the design of trials. They include the incorporation of a thorough process evaluation and stratifying the sample to allow preplanned subgroup analyses stratified by context. If it is feasible to measure the key variables comprehensively and accurately, and to specify the underlying causal model correctly, then causal modelling methods may provide additional insights. Evaluation studies incorporating these elements can go beyond providing overall estimates of effectiveness to show how and why implementation and impact vary within the target group and by context.

\section{Reporting, synthesis and knowledge exchange}

How has context shaped the findings and their interpretation?

How does the relationship between intervention and context reinforce or challenge existing theories of change?

What contexts are the findings applicable to and in what other contexts should future studies be conducted?

\section{Reporting}

Indicating and describing clearly the contexts in which the research was carried out, how they affect implementation and variation in impacts and the limits to the applicability of the results should make reports of primary studies and evidence syntheses more useful to researchers who are considering whether or not to undertake evaluations in other contexts and to decision-makers who are considering whether or not to implement similar interventions. A more appropriate goal than broad generalisation is to aim for better understanding of the factors driving variation in implementation and effectiveness and the applicability of findings from one context, or range of contexts, to another. Edwards and colleagues ${ }^{103}$ and Green and colleagues ${ }^{104}$ followed up their natural experimental evaluation of free bus travel for young people with a qualitative study aimed at identifying the contextual factors and other preconditions necessary for the intervention to achieve its effects.

Although existing reporting guidelines provide some pointers to how information about context should be presented, there is no equivalent of the Template for Intervention Description and Replication (TIDieR) framework for describing interventions ${ }^{105}$ that can be used to guide the reporting of context. Standard 
reporting guidelines such as Consolidated Standards of Reporting Trials (CONSORT), ${ }^{106}$ Strengthening the Reporting of OBservational studies in Epidemiology (STROBE) ${ }^{107}$ and Transparent Reporting of Evaluations with Nonrandomized Designs (TREND), ${ }^{108}$ for trials, observational studies and non-randomised studies of interventions, respectively, include items related to the generalisability of findings, whereas applicability and transferability to and from particular settings are arguably more relevant for population health interventions. ${ }^{109}$ The CONSORT extension for the reporting of pragmatic trials ${ }^{110}$ identifies the trial setting as a key factor distinguishing pragmatic from explanatory trials and recommends that setting should be taken into account in discussing the applicability of trial findings. The World Health Organizations's (WHO) recent guidance for the reporting of implementation research includes a single item on context, defined as 'Success factors, barriers and how they were overcome'. ${ }^{111}$ The Standards for Reporting Implementation Studies (StaRI) statement for the reporting of implementation studies goes further, including context as a distinct item within the reporting of both methods and findings, and recommends the use of the Consolidated Framework for Implementation Research ${ }^{9,31}$ as a basis for identifying relevant dimensions and constructs. ${ }^{112}$

\section{Evidence synthesis and knowledge exchange}

Given the importance of interactions with context for understanding the feasibility and effectiveness of population health interventions, it seems unrealistic to expect broad generalisability in the conclusions of a systematic review, in the sense that the findings will be applicable to any context. Even interventions such as smoke-free public places legislation that have been shown to be effective in a range of contexts may have widely varying effects. ${ }^{113}$ If there are strong dependencies between intervention and context, an intervention that is beneficial in some contexts may even be harmful in others. A systematic review found that a single course of corticosteroids administered to women at risk of preterm birth could substantially reduce neonatal mortality. ${ }^{114}$ All 18 trials included in the meta-analysis were carried out in high- or middle-income countries. The recommendation that steroids be used more widely in preterm births in poorer countries was questioned on the grounds that such births tend to take place outside hospitals, where there is a greater risk of infection. ${ }^{115}$ A subsequent large cluster-randomised trial in six LMICs found no reduction in mortality among premature babies when a corticosteroid was used, but an increased risk of neonatal mortality and maternal infections in the intervention clusters. ${ }^{116}$

Taking account of context can help explain systematic review findings, as well as defining the limits of applicability. For a systematic review of welfare-to-work interventions for lone parents, Gibson and colleagues $^{117}$ extracted data on the political and economic contexts in which the trials were conducted. Many of the trials included in the review were undertaken at times of welfare retrenchment and favourable labour market conditions. This led to high rates of exit from welfare benefits among control groups, which the authors identified as one reason for the small effects observed in the trials. Although useful, taking account of context in systematic reviews is difficult given the lack of reporting of context in primary studies. Langford and colleagues ${ }^{\prime 118,119}$ Cochrane review of trials of interventions based on the WHO's Health Promoting Schools framework found that only two of the 67 eligible studies reported data on school attainment or attendance or how effects vary according to pupils' gender, ethnicity and socioeconomic status (see Chapter 5, Case study 10). The review found that process evaluations tended to focus on implementation fidelity, which is just one of three important functions of process evaluation (alongside understanding of context and mechanisms; see Evaluating interventions), with little attention paid to the social, political or cultural contexts in which the interventions were implemented. Despite the substantial number of trials found in the review, there was therefore little useful evidence to support judgements about the applicability of the framework to other countries or contexts.

The Cochrane Collaboration's 2007 guidance for systematic reviews of public health interventions ${ }^{120}$ notes the importance of taking account of context and the weakness of existing reporting practice in primary studies. It recommends that, in the absence of good information about intervention contexts in reports of evaluation studies, reviewers should be cautious about generalising from one context to another, but should note the presence or absence of context-related information to guide interpretation. The guidance

(c) Queen's Printer and Controller of HMSO 2018. This work was produced by Craig et al. under the terms of a commissioning contract issued by the Secretary of State for Health 
sets out a range of questions for reviewers to use in assessing the applicability and transferability of interventions from one policy or practice context to another.

Likewise, Burford and colleagues ${ }^{25}$ note that synthesising evidence with reference to context is difficult because of poor reporting in primary studies, but recommend that systematic review authors should provide information on the following aspects of context to enable users to assess the applicability of the evidence to their own decision-making:

- descriptions of study settings (geographical, health system, etc.), time periods and populations

- factors affecting intervention implementation identified in the included studies

- baseline prevalences of the health issues of interest in the study populations/settings

- evidence of differential effects across sociodemographic or other groupings

- data from the included studies on the resources required to implement the interventions.

Public health policy-makers and researchers have expressed frustration with systematic reviews that focus on narrow questions and the application of strict quality assessment criteria at the expense of relevance to decision-making. ${ }^{121,122}$ Methods have been developed to aid the synthesis of evidence from natural or quasi-experimental studies using a range of research designs. ${ }^{123}$ Other synthesis approaches such as realist reviews and meta-ethnography can further help address this gap. Realist reviews provide more explanatory evidence by unpacking the mechanism(s) of how and why complex interventions work or do not work, for whom and under which contextual circumstances. ${ }^{124}$ Meta-ethnography regards interpretations in primary qualitative research studies as data and relates, translates and synthesises these 'data' sources by following a series of steps. ${ }^{125}$

$\mathrm{O}^{\prime} \mathrm{Campo}$ and colleagues ${ }^{126}$ conducted a realist review to shed light on how and why unemployment insurance policies impact on poverty and health in different welfare state contexts. To identify the initial theory and mechanisms of action, the authors searched the peer-reviewed and grey literature, but found few relevant articles. Qualitative and quantitative studies that provided in-depth descriptions of mechanisms (i.e. how mechanisms resulted in the outcomes and any related contextual influences) were given more weight. The policy context in each relevant welfare state was explicitly appraised. To supplement the gaps in the literature, the authors conducted key informant interviews with policy-makers, researchers and advocates with knowledge of unemployment insurance policies. This example highlights how a realist review methodology can be rigorously applied to synthesise knowledge from diverse disciplines about upstream policies to reduce inequalities in health with sensitivity to context.

Jamal and colleagues ${ }^{127}$ conducted a systematic review and meta-ethnography of qualitative studies to understand the processes whereby the school environment influences the health of young people. They adapted Noblit and Hare's ${ }^{125}$ approach to meta-ethnography, extracting relevant data from qualitative studies, including information about context. The authors concluded that schooling shaped young people's health through several levels of context, including state education policies, features of the school setting such as staff-student relationships and the use of surveillance technology and pupils' peer networks and socioeconomic backgrounds. ${ }^{127}$ This example highlights how a theory-driven synthesis of qualitative research studies can elucidate context-sensitive findings about how the school environment affects students' health. Further examples of reviews that explore contextual variation in intervention effectiveness include McGill and colleagues'128 review of socioeconomic inequalities in the impact of healthy eating interventions and Forrest and colleagues' ${ }^{\prime 29}$ review of socioeconomic inequalities in lung cancer treatment.

\section{Recommendations}

Reports of public health intervention studies will be most useful if they state clearly how context has shaped the findings, including how context was taken into account in intervention development and study design, how context was measured, which aspects of context mediate or moderate the effects of the intervention and to which contexts the evidence applies. If the findings challenge assumptions of the initial ToC, changes should be captured in a revised version. Often it will not be possible to report all of this 
comprehensively within the constraints of a traditional 'findings' paper, so a series of papers may be needed. Ideally, such papers should be published simultaneously, or in quick succession, and be clearly cross-referenced. Journal editors should consider the publication of linked series of papers to help ensure that findings about impacts are clearly linked to information about context.

Systematic reviews may be more informative if reviewers systematically extract and report contextual information across a range of dimensions, such as those set out in Table 1. If sufficient contextual information is available, it would be helpful for reviewers to describe how effects vary according to context, identify gaps in the information available and make clear the limits to the applicability of their conclusions. 



\title{
Chapter 4 Conclusion and recommendations
}

\begin{abstract}
Researchers should systematically incorporate considerations of context at all stages of the development and evaluation of PHIR interventions, using a comprehensive categorisation of features of context to develop a ToC that should be updated in the light of study findings.
\end{abstract}

Reviews of PHIR should seek to identify the contextual factors of importance in primary studies and draw conclusions about the applicability of findings accordingly.

Journals should emphasise in their guidance for authors and reviewers the requirement for comprehensive and explicit reporting of context.

Research funders should recognise the importance of adequately resourced process evaluation; they should support replication studies that evaluate interventions in novel contexts and methodological work on reporting, evidence synthesis and modelling of contextual influences on variation in implementation and outcomes.

Although the importance of context for PHIR has long been recognised, comprehensive guidance for producers and users of PHIR evidence is lacking. There are many useful pointers in existing guidance, but they are thinly spread across a wide range of documents. We have tried to pull together the key insights and frameworks and to illustrate, with real examples, how they can be applied. We recognise that this is a first step and that more work is needed to develop comprehensive guidance. In the meantime, we offer the following recommendations.

Researchers should systematically incorporate considerations of context at all stages of the development and evaluation of PHIR interventions. Use of a comprehensive categorisation of features of context will help to identify those relevant to understanding processes of change. This understanding can be used to develop a ToC and to guide process evaluation, sample design and analysis. Given the difficulty of anticipating all of the relevant interactions between intervention and context, researchers should be prepared to revise their ToC as the evaluation proceeds. Process evaluation, context-specific sampling schemes and subgroup analyses should be standard features of evaluation designs. When effects are expected to vary significantly according to context, samples may be stratified to allow preplanned context-specific subgroup analyses. Reports of intervention studies will be most useful if they identify the contextual factors associated with implementation success or failure and with variation in outcomes and make explicit statements about the applicability or otherwise of the findings to different contexts. Reviews of PHIR should seek to identify the contextual factors of importance in primary studies, use methods that can capture context-specific change processes, constraints and enablers of implementation and draw conclusions about the applicability of findings accordingly.

Changes to the ways that context is considered in PHIR need to be supported by publishers and funders of research. Some of the issues that we have identified are longstanding and improvement is unlikely to come about by the unaided efforts of researchers. Journal editors can help by considering the publication of linked series of papers to help ensure that findings about impacts can be clearly linked to information about context. Journals should emphasise in their guidance for authors and reviewers the requirement for comprehensive and explicit reporting of context. We encourage research funders to recognise the importance of adequately resourced process evaluation and to support replication studies that evaluate intervention effectiveness in novel contexts. Funders should recognise that, in some circumstances, for example when a promising intervention has been tested in only one highly specific context, replication studies may be a more efficient use of funds than research to develop and test novel interventions. Development work for such studies 
should include explicit consideration of how the new contexts will shape implementation and outcomes and of whether or not and how the intervention will need to be adapted. Funders should also support methodological work on context, including the development of reporting templates to facilitate accurate, comprehensive and systematic reporting of context, approaches to evidence synthesis that can capture contextual variation adequately and modelling methods that can leverage the accumulating evidence on contextual variation to predict the reach, implementation and effectiveness of promising interventions in new contexts.

These are first steps. A comprehensive understanding of interventions in context implies the adoption of a complex systems perspective. It is no accident that 'rhetoric urging complex systems approaches to public health is only rarely operationalised in ways that generate relevant evidence or effective policies'.27 Far-reaching changes to the way that PHIR is funded, conducted and published may be needed to implement such approaches, but a better grasp of the range of aspects of context that need to be taken into account, and of the ways that they shape implementation and effectiveness, is a an essential stage of the process. 


\title{
Chapter 5 Case studies
}

\author{
Stage 1: defining the public health problem and associated \\ research questions
}

\section{Case study 1: Visioning Health II - indigenous, participatory evaluation and assessment of a culturally grounded and arts-informed intervention for human immunodeficiency virus-positive indigenous women}

\section{Intervention}

An intervention research project initiated by indigenous women living with HIV in Canada and developed in partnership with community organisations and academic researchers.

\section{How did the research address context?}

Visioning Health II (VHII) takes context into account by taking guidance from indigenous elders and knowledge keepers, employing traditional and contemporary indigenous arts and engaging locally relevant spiritual and cultural practices, as well as accommodating the lived realities of and supporting leadership by indigenous women living with a HIV infection, to co-create an intervention and its evaluation.

\section{Summary}

Visioning Health II is engaging 40-64 indigenous women living with a HIV infection in eight sites across Canada, attending to regional diversity, co-creating new knowledge on the meaning of health for these women and evaluating the Visioning Health process by measuring important wellness outcomes. ${ }^{130}$ The goals of the project are to (1) conduct research on the meaning of health and how it intersects with gender and culture among indigenous women living with a HIV infection and (2) develop and test the Visioning Health model as an intervention and assess its effectiveness and process.

Visioning Health II is adapting psychometric tools to help capture change over time among indigenous women living with a HIV infection in ways that they indicated were meaningful in Visioning Health I (VHI), yet doing so with the full engagement of the women so that the instruments are culturally appropriate and relevant to their experiences. Women from VHI have formed a Women's Council that actively participates in the governance of the project as well as in instrument development and community research co-ordinator training. Having indigenous women living with a HIV infection as mentors is important to provide role models and support for women new to the Visioning Health process. These and other participating women are being equitably compensated for the costs of taking part, such as for their time, travel and childcare.

Visioning Health is intended to lead to the co-creation of (1) new indigenous HIV-relevant, strengths-based knowledge regarding conceptions of health; (2) indigenous artworks from each group that may be used in culturally relevant health promotion and knowledge transfer and exchange; (3) region- and nation-specific understandings of the intersections between health, culture and gender; (4) a strong network of indigenous women living with HIV across the country; and (5) a manual outlining the essential elements of Visioning Health as a health-promotion intervention. It is also anticipated that participants in VHII will report improvement in self-defined health, including a stronger sense of connectedness, self-determination (self-mastery) and social support. 


\section{Case study 2: preventing exposure of children to foods high in fat, salt and} sugar - evaluation of the Office for Communications Regulation regulation of television advertising

\section{Intervention}

Regulation of the advertising of foods high in salt, fat and sugar during children's television programmes in the UK.

\section{How did the research address context?}

Research on the links between the interests of stakeholders responding to a policy consultation on the regulation of advertising and the final form of the regulation identified the predominant influence of industry stakeholders. Identifying which voices carry most weight within the context for intervention development can help to explain the eventual form of the intervention and its implications for population health outcomes.

\section{Summary}

Foods high in salt, fat and sugar (usually ultra-processed) are known to be associated with a range of chronic diseases, in particular obesity. Over many years, concern has been raised about the consumption of such foods by children, leading to calls for restrictions on their promotion and marketing to children. In 2006, the UK government initiated a process to introduce regulation of the extent of marketing of such foods to children on television by regulating advertising of such foods during programming watched by children. The intervention was developed by the UK television advertising regulator (Ofcom). The regulator developed proposals in consultation with a range of parties, including the food industry and the advertising industry, culminating in a public consultation on specific proposals. The resultant regulations were implemented between 2007 and 2009.

Ofcom's own evaluation of the regulation claimed that it had been successful. ${ }^{51}$ An independent evaluation of the impacts on children's and adults' exposure to the advertising of foods high in fat, salt and sugar showed that, although the regulation had led to a reduction of exposure during children's television programmes, there had been an overall increase in exposure, in particular during prime-time television programmes, many of which are watched by children as well as adults. ${ }^{52}$

More recent research has explored the strategies used by different stakeholders in responding to the Ofcom consultation and the extent to which these were associated with the final form of the regulations. Food industry responses appeared more likely to have shaped the regulations, whereas those from health interests may have carried less weight (Rizavi S, Adams J, White M. Do Commercial, Consumer, Health or Civil Society Organisations Influence Public Health Policy and If So, How? Qualitative Study of Responses to the Ofcom Consultation on Regulation of TV Advertising to Children of Foods High in Fat, Salt and Sugar. MRC Epidemiology Unit, University of Cambridge; 2017).

This case shows that the context in which an intervention is developed - and, in particular, which stakeholders have the greatest influence over intervention development - can have profound implications for the resultant intervention and consequent health outcomes.

\section{Case study 3: establishing leadership hubs to improve nursing care for human} immunodeficiency virus/acquired immune deficiency syndrome patients in four low- and middle-income countries - understanding system and organisational dimensions of context

\section{Intervention}

District/parish leadership hubs to improve clinical practices and workplace policies related to the care of people with HIV and their families in Kenya, Uganda, South Africa and Jamaica. 


\section{How did the research address context?}

Development of the leadership hubs was informed by research to understand contemporary and historical contextual influences on the way that nursing care is provided to patients with HIV in four African countries. Participatory action research was used as a basis for the design and adaptation of HIVIAIDS care improvement interventions by hub members to reflect their local (workplace organisations and district/parish health system) and national contexts. Hubs developed an evaluation project to examine a quality care issue that was pertinent to their setting and used project results to leverage workplace improvements. Qualitative and quantitative findings were triangulated to examine organisational and system influences on care gaps. ${ }^{131}$

\section{Summary}

Nurses make up the majority of front-line health-care workers in most LMICs and are the main providers of care for patients with HIV-infected and their families. In caring for these patients, they experience risks such as needle-stick injuries and stigmatisation. These risks are exacerbated by difficult working conditions. ${ }^{132-134}$ Nurses tend to be excluded from traditional hierarchies of power and influence within the health professions in LMICs and so are rarely involved in developing clinical guidelines and workplace policies designed to reduce risk. ${ }^{133,135}$

A mixed-methods programme of research was undertaken between 2008 and $2012^{57,58}$ to examine the impact of district leadership hubs established by the research team in four countries (Kenya, Uganda, South Africa and Jamaica). The hubs engaged nurses and other members of the district teams in a participatory action research approach that aimed to improve clinical practices and workplace policies related to the care of people with HIV-infected and their families. Hub members included district decision-makers, nurses and other health professionals working in primary, secondary and tertiary care and those living with a HIV infection or AIDS.

A quasi-experimental study design was used to assess the impact of the hubs. Quantitative measures included the self-assessed leadership capacity of hub members and pre- and post-surveys of clinical care practices, workplace policies, stigma and human resource management policies. Qualitative interviews and focus groups assessed nurses' experience of providing HIV care and the experience of participating in hub activities. Contextual factors that influenced the hubs were captured by reviewing action plans, holding debriefing sessions with the research assistants who interacted regularly with hub members and conducting qualitative interviews with hub members about their experiences. The researchers also documented local influences on the hub intervention such as major health-care reforms or local crises (e.g. natural disasters and epidemics) that prevented hub members from participating in the hub either temporarily or permanently. These data were used to develop a comprehensive contextualised account of the intervention and its uptake; this in turn informed interpretation of study outcomes ${ }^{58,136}$ and provides guidance for contextualising clinical practice guidelines. ${ }^{137}$

\section{Stage 2: developing and adapting interventions}

\section{Case study 4: AmaQhawe - a community empowerment approach to adapting a complex intervention}

\section{Intervention}

A primary school based intervention for pre-adolescent children and their caregivers to reduce HIV infection among adolescents by improving HIV knowledge, reducing HIV stigma and strengthening caregiver-child connectedness, communication, monitoring and control.

\section{How did the research address context?}

A complex HIV prevention intervention developed in the USA was adapted for use in South Africa. A community collaborative empowerment framework was used to identify factors specific to the South African context. These contextual factors which were addressed in a revised version of the intervention that was piloted, further adapted and tested in a randomised trial. 


\section{Summary}

The Collaborative HIV/AIDS Adolescent Mental Health Programme was developed for African American people and adapted for South Africa as the AmaQhawe (Champions) programme. ${ }^{67-69}$ A quasi-experimental study of CHAMP in Chicago found that it was associated with increased parental knowledge of HIV, decision-making and comfort in family communication. ${ }^{138} \mathrm{~A}$ trial of AmaQhawe in South Africa showed improved parent-child communication about sensitive topics, improved parental monitoring and control and strengthened primary social networks for caregivers. ${ }^{67}$ Both evaluations involved people who had contributed to the programme's design.

This intervention is premised on the recognition that adolescents' HIV-related behaviour is shaped by their social environment and that prevention should be at multiple socioecological levels. The AmaQhawe programme addresses the family and community levels following a qualitative, ethnographic needs assessment. This identified key broad contextual factors that exacerbate the epidemic: the apartheid legacy; patriarchal culture; macro-level sociocultural changes that threaten traditional parental roles, especially advocacy of children's rights; fractured leadership that cannot respond constructively to these changes, leading to social divisions and mistrust; and children's schooling outstripping their parents' educational level. At the interpersonal level, contextual factors are parental disempowerment, harsh parenting, poor parent-child communication, parental ignorance about HIV and death of relatives.

The main ways in which the AmaQhawe programme has taken account of the different context of South Africa is by (1) incorporating sessions on stigma and bereavement; (2) adding a session on parent and child rights and responsibilities; (3) using cartoon narratives to address sexual topics, which cultural taboos make very sensitive to discuss; and (4) facilitating a more health-enhancing community context through building social competence and collective efficacy.

\section{Case study 5: babyClear - an intervention to prevent smoking in pregnancy}

\section{Intervention}

A new care pathway to enable midwives to engage effectively with pregnant smokers in the North East region of England.

\section{How did the research address context?}

Interviews with midwives and pregnant smokers were used to develop an understanding of the health-care context in which smoking cessation advice is delivered. This understanding helped inform the development of an effective and cost-effective intervention, delivered at scale, with substantial impact on rates of smoking in pregnancy.

\section{Summary}

The North East region of England has the highest rates of smoking in pregnancy. Prior research on tackling smoking in pregnancy has tended to focus on the choices made by pregnant women, albeit in the context of their everyday lives, with low socioeconomic position playing a key determining role. ${ }^{139}$ However, the context of the interactions between pregnant smokers and their health carers had not been fully investigated.

To understand why stop smoking services that were working well in other population groups were not working in pregnant women, the researchers explored the influence of the care system from the perspectives of midwives and pregnant smokers. They found that midwives' reluctance to raise the issue of smoking for fear of damaging their relationship with pregnant women lay at the heart of the problem. ${ }^{70}$ This led to the commissioning of a novel intervention across the North East, which was evaluated using an interrupted time series study, together with economic, and quantitative and qualitative process evaluations. ${ }^{71}$

Initial research identified the importance of midwives engaging with smoking cessation and what were the barriers to them doing so. ${ }^{70}$ These barriers were addressed in a novel intervention (babyClear), which introduced a new care pathway, training for midwives and other relevant staff, routine carbon monoxide 
monitoring of pregnant smokers and a more intensive behavioural intervention coupled with routine ultrasound scans for persistent smokers. ${ }^{71}$

The intervention was highly effective, increasing the referral rate to stop smoking services and almost doubling the probability of quitting. Babies born to women who had quit smoking by delivery had a significantly higher birthweight than those whose mothers continued smoking. The additional cost per delivery was $\mathrm{f3} 1$ and the incremental cost per additional quit was $£ 952 ; 31$ pregnant women needed to be treated for each additional quitter.

\section{Case study 6: Football Fans in Training}

\section{Intervention}

A 12-week group-based intervention delivered by community coaches within professional football clubs to encourage overweight/obese men [body mass index $(\mathrm{BMI})>28 \mathrm{~kg} / \mathrm{m}^{2}$ ] aged 35-65 years to lose weight through adopting a healthier lifestyle.

\section{How did the research address context?}

Engaging middle-aged men in weight loss interventions is difficult. In this study, careful attention to the physical and cultural context of intervention delivery enabled the development of an intervention that could attract high-risk participants. FFiT provides an environment in which the men are supported, and support each other, to make long-term behavioural changes. FFiT also demonstrates that the context of delivery of an intervention can facilitate changed performances of masculinity in relation to health.

\section{Summary}

Football Fans in Training is a weight management and healthy living programme, gender sensitised to appeal to men in context, content and style of delivery. Its development drew on best evidence for behaviour change interventions and sociological theories of masculinities in relation to health. ${ }^{140} \mathrm{~A}$ two-stage developmental and pilot study involving participant and coach feedback, focus group discussions and interviews explored the utility and acceptability of programme components and identified suggestions for improvement. ${ }^{140}$ Programme sessions were observed to identify examples of good practice and problems with delivery. The findings were used to optimise the intervention and map its components onto specific behaviour change techniques using an evidence-based taxonomy.

Following the pilot, FFiT was delivered in 13 Scottish professional football clubs and evaluated in a pragmatic randomised controlled trial with an integrated process evaluation. ${ }^{74}$ The study was designed to assess effectiveness and cost-effectiveness, fidelity of delivery and coach and participant experiences. Semistructured interviews with participants and staff, focus groups with participants and observations of delivery during the pilot and full-scale trials were used to explore the extent to which the physical and cultural context of FFiT attracted and engaged high-risk men and supported them in making lifestyle changes to support weight loss.

Football Fans in Training was effective in achieving weight loss and lifestyle changes at 12 months. ${ }^{74,141}$ Delivering FFiT within the physical context of professional football clubs proved successful in attracting men across the socioeconomic spectrum who were at high risk of ill health or future ill health and provided a symbolic and culturally appealing context for these men. Taking part in FFiT in this context with other men who were perceived to have common interests and common physical/health challenges also promoted a relational context in which men were able and willing to assimilate new health information, support each other to make lifestyle changes and renegotiate health practices that were congruent with their daily lives and valued performances of masculinity. ${ }^{72,73,142}$ FFiT is now routinely implemented in many professional football clubs across the UK and its potential for wider implementation is now being tested in a wide range of other sports and non-sport settings, countries and population groups. 


\title{
Stage 3: evaluating interventions
}

\author{
Case study 7: A Stop Smoking in Schools Trial - a peer-led smoking prevention \\ intervention for use with students in secondary schools
}

\section{Intervention}

A smoking prevention intervention in which secondary school students aged 12-13 years identify their most influential peers, who are then invited to train as peer supporters.

\section{How did the research address context?}

Trials in which randomisation takes place within a single context cannot identify contextual influences on delivery or outcomes. If sampling and randomisation are stratified by context, such influences can be explored through preplanned subgroup analyses. In this pragmatic cluster randomised controlled trial, ${ }^{90}$ stratified sampling and randomisation across the trial arms ensured representation of a wide variety of different contexts and enhanced the applicability of the findings. Prespecified subgroup analyses were used to examine differential intervention effects according to important contextual factors. An embedded process evaluation ${ }^{143,144}$ was used to assess how key stakeholders and the target population engaged with the A Stop Smoking in Schools Trial (ASSIST) programme; whether or not the intervention was delivered consistently and how that might be related to context; and whether or not the intervention worked in accordance with its underlying theory.

\section{Summary}

The ASSIST programme was evaluated in a pragmatic cluster randomised controlled trial in 59 schools in south-east Wales and south-west England. ${ }^{90}$ Thirty schools were randomised to receive the ASSIST intervention in addition to their usual smoking education provision and 29 schools were randomised to continue with their usual smoking education only. The main outcome measure was weekly smoking at both the school and the individual level.

The focus on context led to a stratified sampling and randomisation strategy to ensure that a wide variety of schools was recruited, including state and privately funded schools, co-educational and single-sex schools, different-sized schools, Welsh-medium and English-language schools and schools in England and Wales. The quantitative analysis took account of context by including a series of subgroup analyses to explore whether or not the intervention had differential effects. These analyses showed that the intervention worked particularly well in tight-knit communities, such as those in the south Wales valleys, served by a single secondary school where peer supporters were in regular contact with their peers.

The process evaluation ${ }^{143,144}$ revealed that peer supporters worked in a context-specific way, making pragmatic decisions about which of their peers they would be able to persuade not to take up smoking and focusing their efforts on them. This, and the particular success of the intervention in schools in the Welsh valleys, suggested that the ASSIST programme was working in a way that was consistent with diffusion of innovation theory, which underpinned the intervention design.

\section{Case study 8: a national subsidy policy for birth deliveries in Burkina Faso}

\section{Intervention}

A national policy of subsidising the cost of giving birth in a health facility. Under the policy, women paid $20 \%$ of the cost of delivery, with the rest being paid by the state; the poorest were fully exempted. Health centres were reimbursed with a lump sum on the basis of the number of deliveries performed.

\section{How did the research address context?}

This mixed-methods natural experimental evaluation showed that, although the policy increased the use of health facilities, uptake varied widely and inequalities persisted between districts, health centres and women. Contextual factors that affected uptake included household income, distance from a health facility, staff-patient power relations and the effectiveness of local leadership. 


\section{Summary}

Giving birth in a health facility with qualified personnel rather than at home is strongly associated with lower maternal mortality in low-income countries. Faced with a very high rate of maternal mortality and a very low rate of assisted delivery, Burkina Faso enacted a national policy to subsidise the cost of delivery. Its aims were to encourage use of health facilities and reduce maternal mortality. Belaid and colleagues, ${ }^{92}$ De Allegri and colleagues ${ }^{93}$ and Ridde and colleagues ${ }^{94}$ conducted a mixed-method natural experimental evaluation of the policy. The quantitative studies showed that the policy led to greater use of health facilities for delivery and substantially reduced women's health expenditure, but there was wide variation in the extent and timing of the increase in use of health facilities within and between districts and health centres. A contrasted multiple case study approach was used to identify contextual factors that could explain variation in outcomes. ${ }^{92}$

Statistical data from the health information system showed three different outcomes across areas of one district, Djibo. ${ }^{92}$ In some areas, the use of health facilities increased immediately after the policy was introduced, in some areas use increased only 6 months later and in other areas there was no change. As routine data could not explain these variations, six studies of contrasted cases were conducted to explore the role of individual and organisational factors identified through a review of the literature as possible influences on the use of assisted deliveries. ${ }^{92}$ Immediate improvements in outcomes occurred when health professionals provided leadership to promote assisted delivery and when female health personnel were brought in to strengthen the community's confidence and women's positive perceptions of the quality of care. In health centres in which the policy had no effect, women were observed to have a negative perception of the quality of care, nothing was being done to promote assisted delivery and there were significant conflicts among health professionals and users.

In another district, Nouna, quantitative analysis of household survey data were combined with a qualitative study using a maximum variation sample of women and villages. ${ }^{93}$ Analysis of the survey data suggested that distance and household income remained significant barriers to the use of health facilities, even when health-care costs were subsidised. There was additional village-level variance in rates of home delivery, which could not be explained by any of the village-level variables. The subsequent qualitative study confirmed the major role of distance and household income and suggested that cultural factors, which are often assumed to be critical, were relatively unimportant..$^{93}$

\section{Case study 9: the iConnect and Commuting and Health in Cambridge studies of new transport infrastructure}

\section{Intervention}

Infrastructure to encourage walking, cycling and use of public transport, including traffic-free paths and cycle routes and a new public transport system (a guided busway).

\section{How did the research address context?}

The iConnect ${ }^{95}$ and Commuting and Health in Cambridge ${ }^{96}$ studies used subgroup analysis and causal modelling methods to identify causal mechanisms linking exposure to the intervention with subsequent behaviour change and explored how the mechanisms were related to and interacted with the context. The researchers used the results of these analyses to explain divergent findings of the main outcome analyses and to interpret the findings for users in other contexts.

\section{Summary}

The studies used controlled quasi-experimental methods to evaluate the impacts of building new infrastructure for walking, cycling and public transport on the travel and physical activity behaviour of local people. In both studies, there was clear evidence of a significant intervention effect that was robust to adjustment for multiple observed confounders. ${ }^{95,96}$ Rather than specifying and testing a single mediating relationship, the investigators adopted a socioecological perspective on behaviour change and hypothesised a more complex set of causal mechanisms - involving changes in perceptions of the physical and social environments and use of the new routes, as well as constructs of the theory of planned behaviour - and formally tested these using path regression. 
These analyses showed that the majority of the behaviour change attributable to living closer to the interventions was mediated simply by use of the new routes - thus, confirming the causal attribution of the main effects - and found little statistical evidence that changes in cognitions or perceptions contributed to mediating of the effects. ${ }^{97,98}$ These findings could be regarded as being consistent with a hypothesis that behaviour change can be promoted by altering environmental cues, without explicitly encouraging the target behaviours or directly addressing people's cognitions. As with all mediation analyses, however, the lack of evidence for certain hypothesised causal pathways could also reflect limitations in the sample size available for analysis and in the selection and measurement of the mediator variables.

Causal inference in public health often entails making judgements about various assortments of 'ragged evidence' and it would therefore be unwise to rely entirely on a single, statistical method for inferring causal relationships. ${ }^{8,145,146}$ In both studies, for example, complementary qualitative and mixed-method analyses elicited plausible causal processes in which altering perceptions of the environment may have been important for triggering behaviour change in different groups and at different intervention sites (i.e. in different contexts) 99,100 and stratified path regression models identified different causal pathways in groups of people with higher or lower levels of activity prior to the intervention. ${ }^{97}$ Analyses showed how - in a particular context - an intervention could reduce the physical activity of some commuters, by shortening the length of their cycle route to work or by increasing the attractiveness of the competing public transport service. ${ }^{98}$

\section{Stage 4: reporting, synthesis and knowledge exchange}

\section{Case study 10: a Cochrane systematic review of the World Health Organization health-promoting school framework}

\section{Intervention}

The WHO Health Promoting School framework (known in the USA as Comprehensive School Health Education) combines health education in the school curriculum with changes to the school environment and ethos and engagement with parents and the wider community. An intervention might include (1) teaching on the benefits to health of being physically active, (2) promoting active travel to school by providing bicycle racks and in-school cycle training and (3) work with parents and the wider community to promote students' health through activities such as helping to organise local family cycling events and working with the local authority to ensure safe cycling routes to school.

\section{How did the research address context?}

The review assessed the extent to which trials of health-promoting school interventions took context into account, whether or not they included a process evaluation, whether or not they measured relevant non-health outcomes such as educational attainment or attendance and whether or not they analysed impacts according to key equity criteria such as gender, socioeconomic background and ethnicity.

\section{Summary}

The review synthesised evidence from cluster randomised controlled trials on the effectiveness of interventions using the Health Promoting Schools framework for improving the health, well-being and educational achievement of school students. ${ }^{118,119}$

Sixty-seven studies were included in the review. The review found evidence of small intervention effects, indicative of public health benefit, for physical activity, physical fitness, fruit and vegetable intake, BMI, tobacco use and being bullied. There was limited evidence of intervention effectiveness for standardised body mass index (zBMI) and none for fat intake, alcohol use, drug use, mental health, violence and bullying others. Only two studies conducted cost-effectiveness evaluations. Data on academic attainment 
was rarely collected and so the review could not come to any conclusion about the impact of Health Promoting Schools interventions on this important outcome.

The review drew attention to important aspects of context missing from the included studies and made recommendations about this should be addressed in future. Strikingly, although the context for these interventions was school, only two studies reported outcome data on school attainment or attendance, even though such data are likely to influence any decision to scale up implementation of Health Promoting Schools interventions. Process evaluations tended to be dominated by issues of implementation fidelity and, to a lesser extent, acceptability, with few considering the social, cultural or political contexts surrounding implementation, making judgements about the extent to which interventions would be transferable to other countries and school contexts difficult. Only eight included studies had been conducted in LMICs. Very few studies assessed the impact of interventions according to important equity criteria such as gender, ethnicity and socioeconomic status. 



\section{Acknowledgements}

Droject management was provided by Hannah Dorling, Research Fellow at the NIHR (2015), and

Genevieve Baker, Research Manager at the NIHR (2016-17).

The views expressed in this publication are those of the authors and do not necessarily represent those of the CIHR or its IPPH, the NIHR or the UK Department of Health and Social Care.

\section{Contributions of authors}

Peter Craig (Senior Research Fellow, MRC/CSO Social and Public Health Sciences Unit, University of Glasgow) provided substantive intellectual input at a workshop in London, UK, in November 2015; agreed the content of the document; prepared an initial outline of the document (with further input provided by other members of the editorial group); prepared a first full draft of the document; attended a second workshop in Ottawa, Canada, in April 2016, and provided substantive intellectual input to the further development of the document; and revised successive drafts of the document (with substantive input from other members of the editorial group).

Erica Di Ruggiero (Director of the Office of Global Public Health Education and Training, Dalla Lana School of Public Health, University of Toronto) conceived the idea for the work; provided substantive intellectual input at a workshop in London, UK, in November 2015; agreed the content of the document; and attended a second workshop in Ottawa, Canada, in April 2016, and provided substantive intellectual input to the further development of the document.

Katherine L Frohlich [Professor, Public Health Research Institute (IRSPUM) and School of Public Health (ESPUM), University of Montréal)] provided substantive intellectual input at a workshop in London, UK, in November 2015; agreed the content of the document; and attended a second workshop in Ottawa, Canada, in April 2016, and provided substantive intellectual input to the further development of the document.

Eric Mykhalovskiy (Professor, Department of Sociology, York University, Toronto) provided substantive intellectual input at a workshop in London, UK, in November 2015; agreed the content of the document; and attended a second workshop in Ottawa, Canada, in April 2016, and provided substantive intellectual input to the further development of the document.

Martin White (Professor, Centre for Diet and Activity Research, MRC Epidemiology Unit, University of Cambridge) provided substantive intellectual input at a workshop in London, UK, in November 2015; agreed the content of the document; attended a second workshop in Ottawa, Canada, in April 2016, and provided substantive intellectual input to the further development of the document; and provided case studies.

Rona Campbell (Professor, Department of Population Health Sciences, University of Bristol) provided substantive intellectual input at a workshop in London, UK, in November 2015; attended a second workshop in Ottawa, Canada, in April 2016, and provided substantive intellectual input to the further development of the document; and provided case studies.

Steven Cummins (Professor, Department of Social and Environmental Health, London School of Hygiene and Tropical Medicine) provided substantive intellectual input at a workshop in London, UK, in November 2015; and provided substantive intellectual input to the further development of the document.

(C) Queen's Printer and Controller of HMSO 2018. This work was produced by Craig et al. under the terms of a commissioning contract issued by the Secretary of State for Health 
Nancy Edwards (Professor, Faculty of Health Sciences, University of Ottawa) conceived the idea for the work; provided substantive intellectual input at a workshop in London, UK, in November 2015; attended a second workshop in Ottawa, Canada, in April 2016, and provided substantive intellectual input to the further development of the document; and provided case studies.

Kate Hunt (Professor, MRC/CSO Social and Public Health Sciences Unit, University of Glasgow) provided substantive intellectual input at a workshop in London, UK, in November 2015; attended a second workshop in Ottawa, Canada, in April 2016, and provided substantive intellectual input to the further development of the document; and provided case studies.

Frank Kee (Professor, UKCRC Centre of Excellence for Public Health Research, Northern Ireland) provided substantive intellectual input at a workshop in London, UK, in November 2015; attended a second workshop in Ottawa, Canada, in April 2016, and provided substantive intellectual input to the further development of the document; and provided case studies.

Charlotte Loppie (Professor, Faculty of Human and Social Development, University of Victoria) provided substantive intellectual input at a workshop in London, UK, in November 2015; attended a second workshop in Ottawa, Canada, in April 2016, and provided substantive intellectual input to the further development of the document; and provided case studies.

Laurence Moore (Professor, MRC/CSO Social and Public Health Sciences Unit, University of Glasgow) drafted discussion papers that informed development of the ideas; provided substantive intellectual input at a workshop in London, UK, in November 2015; provided substantive intellectual input to the further development of the document; and reviewed the final draft of the document.

David Ogilvie (Programme Leader, Centre for Diet and Activity Research, MRC Epidemiology Unit, University of Cambridge) provided substantive intellectual input to the further development of the document and provided case studies.

Mark Petticrew (Professor, Faculty of Public Health and Policy, London School of Hygiene and Tropical Medicine) conceived the idea for the work; drafted discussion papers that informed development of the ideas; provided substantive intellectual input at a workshop in London, UK, in November 2015; attended a second workshop in Ottawa, Canada, in April 2016, and provided substantive intellectual input to the further development of the document; and reviewed the final draft of the document.

Blake Poland (Associate Professor, Dalla Lana School of Public Health, University of Toronto) provided substantive intellectual input at a workshop in London, UK, in November 2015; attended a second workshop in Ottawa, Canada, in April 2016 and provided substantive intellectual input to the further development of the document; and provided case studies.

Valéry Ridde [Professor, Public Health Research Institute (IRSPUM) and Department of Social and Preventive Medicine, University of Montreal] provided substantive intellectual input at a workshop in London, UK, in November 2015; attended a second workshop in Ottawa, Canada, in April 2016, and provided substantive intellectual input to the further development of the document; and provided case studies.

Jeannie Shoveller (Professor, UBC School of Population and Public Health, University of British Columbia) drafted discussion papers that informed development of the ideas; attended a second workshop in Ottawa, Canada, in April 2016, and provided substantive intellectual input to the further development of the document; and reviewed the final draft of the document. 
Sarah Viehbeck (Adjunct Professor, School of Public Health and Health Systems, University of Waterloo, and Interdisciplinary School of Health Sciences, University of Ottawa) conceived the idea for the work; provided substantive intellectual input at a workshop in London, UK, in November 2015; and attended a second workshop in Ottawa, Canada, in April 2016, and provided substantive intellectual input to the further development of the document.

Daniel Wight (Professor, MRC/CSO Social and Public Health Sciences Unit, University of Glasgow) provided substantive intellectual input to the further development of the document; and provided case studies.

Finally, all co-authors reviewed and approved the final version of the document.

\section{Contributions of others}

Catherine Law (Director of the NIHR PHR programme, 2008-14) conceived the idea for the work (along with Erica Di Ruggiero, Nancy Edwards, Mark Petticrew and Sarah Viehbeck).

Hilary Graham, Penny Hawe, Katie Conte, Jennie Popay, Emma Halliday, Lois Orton and Eva Rehfuess provided independent peer review. 



\section{References}

1. Pawson R, Tilley N. Realist Evaluation. London: Sage; 1997.

2. Birch S. As a matter of fact: evidence-based decision-making unplugged. Health Econ 1997;6:547-59. https://doi.org/10.1002/(SICI)1099-1050(199711)6:6<547::AID-HEC307>3.0.CO;2-P

3. Rychetnik L, Frommer M, Hawe $P$, Shiell $A$. Criteria for evaluating evidence on public health interventions. J Epidemiol Community Health 2002;56:119-27. https://doi.org/10.1136/ jech.56.2.119

4. Green L, Glasgow R. Evaluating the relevance, generalisability and applicability of research. Issues in external validation and translation methodology. Eval Health Prof 2006;29:126-53. https://doi.org/10.1177/0163278705284445

5. Hawe P, Shiell A, Riley T, Gold L. Methods for exploring implementation variation and local context within a cluster randomised community intervention trial $J$ Epidemiol Community Health 2004;58:788-93. https://doi.org/10.1136/jech.2003.014415

6. Hawe P, Shiell A, Riley T. Theorising interventions as events in systems. Am J Community Psychol 2009;43:267-76. https://doi.org/10.1007/s10464-009-9229-9

7. Moore GF, Audrey S, Barker M, Bond L, Bonell C, Hardeman W, et al. Process evaluation of complex interventions: Medical Research Council guidance. BMJ 2015;350:h1258. https://doi.org/ 10.1136/bmj.h1258

8. Vandenbroucke JP, Broadbent A, Pearce N. Causality and causal inference in epidemiology: the need for a pluralistic approach. Int J Epidemiol 2016;45:1776-86. https://doi.org/10.1093/ ije/dyv341

9. Damschroder L, Aron DC, Keith RE, Kirsh SR, Alexander JA, Lowery JC. Fostering implementation of health services research findings into practice: a consolidated framework for advancing implementation science. Implement Sci 2009;4:50. https://doi.org/10.1186/1748-5908-4-50

10. May CR, Johnson M, Finch T. Implementation, context and complexity. Implement Sci 2016;11:141. https://doi.org/10.1186/s13012-016-0506-3

11. Ridde V. Need for more and better implementation science in global health. BMJ Glob Health 2016;1:e000115. https://doi.org/10.1136/bmjgh-2016-000115

12. Frohlich $\mathrm{KL}$, Potvin L. Transcending the known in public health practice: the inequality paradox: the population approach and vulnerable populations. Am J Public Health 2008;98:216-21. https://doi.org/10.2105/AJPH.2007.114777

13. Lorenc $T$, Petticrew $M$, Welch $V$, Tugwell P. What types of interventions generate inequalities? Evidence from systematic reviews. J Epidemiol Community Health 2013;67:190-3. https://doi.org/ 10.1136/jech-2012-201257

14. White M, Adams J, Heywood P. How and Why do Interventions that Increase Health Overall Widen Inequalities Within Populations? In Babones S, editor. Health Inequality and Society. Bristol: Policy Press; 2009. pp. 65-82. https://doi.org/10.1332/policypress/9781847423207.003.0005

15. Chalmers I, Bracken MB, Djulbegovic B, Garattini S, Grant J, Gülmezoglu AM, et al. How to increase value and reduce waste when research priorities are set. Lancet 2014;383:156-65. https://doi.org/10.1016/S0140-6736(13)62229-1

16. Howarth E, Devers K, Moore G, O'Cathain A, Dixon-Woods M. Contextual issues and qualitative research. Health Serv Deliv Res 2016;4(16). 
17. Poland B, Frohlich K, Haines RJ, Mykhalovskiy E, Rock M, Sparks R. The social context of smoking: the next frontier in tobacco control? Tob Control 2006;15:59-63. https://doi.org/10.1136/ tc. 2004.009886

18. Pfadenhauer LM, Gerhardus A, Mozygemba K, Lysdahl KB, Booth A, Hofmann B, et al. Making sense of complexity in context and implementation: the Context and Implementation of Complex Interventions (CICI) framework. Implement Sci 2017;12:21. https://doi.org/10.1186/ s13012-017-0552-5

19. Pfadenhauer LM, Mozygemba K, Gerhardus A, Hofmann B, Booth A, Lysdahl KB, et al. Context and implementation: a concept analysis towards conceptual maturity. Z Evid Fortbild Qual Gesundhwes 2015;109:103-14. https://doi.org/10.1016/.zefq.2015.01.004

20. Shoveller J, Viehbeck S, Di Ruggiero E, Greyson D, Thomson K, Knight R. A critical examination of representations of context within research on population health interventions. Crit Public Health 2015;26:487-500. https://doi.org/10.1080/09581596.2015.1117577

21. Holman $D$, Lynch $R$, Reeves $A$. How do health behaviour interventions take account of social context? A literature trend and co-citation analysis [published online ahead of print 1 March 2017]. Health 2017. https://doi.org/10.1177/1363459317695630

22. Hawe P, Potvin L. What is population health intervention research? Can J Public Health 2009;100(Suppl.):I8-14.

23. Hawe $P$, Di Ruggiero E, Cohen E. Frequently asked questions about population health intervention research. Can J Public Health 2012;103:e468-71.

24. Sniehotta FF, Araúijo-Soares V, Brown J, Kelly MP, Michie S, West R. Complex systems and individual-level approaches to population health: a false dichotomy? Lancet Public Health;2:e396-e7.

25. Burford B, Lewin S, Welch V, Rehfuess E, Waters E. Assessing the applicability of findings in systematic reviews of complex interventions can enhance the utility of reviews for decision making. J Clin Epidemio/ 2013;66:1251-61. https://doi.org/10.1016/j.jclinepi.2013.06.017

26. Montgomery P, Underhill K, Gardner F, Operario D, Mayo-Wilson E. The Oxford Implementation Index: a new tool for incorporating implementation data into systematic reviews and metaanalyses. J Clin Epidemio/ 2013;66:874-82. https://doi.org/10.1016/j.jclinepi.2013.03.006

27. Rutter H, Savona N, Glonti K, Bibby J, Cummins S, Finegood DT, et al. The need for a complex systems model of evidence for public health. Lancet 2017;390:2602-4. https://doi.org/10.1016/ s0140-6736(17)31267-9

28. Brainard J, Hunter PR. Do complexity-informed health interventions work? A scoping review. Implement Sci 2016;11:127. https://doi.org/10.1186/s13012-016-0492-5

29. Edwards N, Di Ruggiero E. Exploring which context matters in the study of health inequities and their mitigation. Scand J Public Health 2011;39(Suppl. 6):43-9. https://doi.org/10.1177/ 1403494810393558

30. Poland B, Krupa G, McCall D. Settings for health promotion: an analytic framework to guide intervention design and implementation. Health Promot Pract 2009;10:505-16. https://doi.org/ $10.1177 / 1524839909341025$

31. Consolidated Framework for Implementation Research (CFIR). Ann Arbor, MI: CFIR Research Team. URL: http://cfirguide.org/index.html (accessed 12 February 2018).

32. Vanderkruik R, McPherson ME. A contextual factors framework to inform implementation and evaluation of public health initiatives. Am J Evaluation 2016;38:348-59. https://doi.org/10.1177/ 1098214016670029 
33. Edwards N, Barker PM. The importance of context in implementation research. J Acquir Immune Defic Syndr 2014;67(Suppl. 2):157-62. https://doi.org/10.1097/QAI.0000000000000322

34. Salway S, Green J. Towards a critical complex systems approach to public health. Crit Public Health 2017;27:523-4. https://doi.org/10.1080/09581596.2017.1368249

35. Best J. Constructing the sociology of social problems: Spector and Kitsuse twenty-five years later. Sociol Forum 2002;17:699-706. https://doi.org/10.1023/A:1021037709754

36. Hacking I. The Social Construction of What? Cambridge, MA: Harvard University Press; 1999.

37. Holstein JA, Miller G. Reconsidering Social Constructionism: Debates in Social Problems Theory. New Brunswick, NJ: Transaction Publishers; 2006.

38. Schneider J. Social problems theory: the constructionist view. Annu Rev Sociol 1985;11:209-229. https://doi.org/10.1146/annurev.so.11.080185.001233

39. Foucault M, Burchell G, Gordon C, Miller P. The Foucault Effect: Studies in Governmentality. Chicago, IL: University of Chicago Press; 1991.

40. Emirbayer M. Manifesto for a relational sociology. Am J Sociol 1997;103:281-37. https://doi.org/ $10.1086 / 231209$

41. Canadian Sociological Association. What is RS? URL: www.csa-scs.ca/files/webapps/csapress/ relational/what-is-relational-sociology/ (accessed 22 February 2018).

42. Bilodeau A, Potvin L. Unpacking complexity in public health interventions with the actor-network theory. Health Promot Int 2018;33:173-81.

43. Smith ER, Conrey FR. Agent-based modeling: a new approach for theory building in social psychology. Pers Soc Psychol Rev 2007;11:87-104. https://doi.org/10.1177/1088868306294789

44. Department of Health and Social Care. The Public Health Responsibility Deal. Department of Health and Social Care; 2011. URL: https://responsibilitydeal.dh.gov.uk/wp-content/uploads/2012/ 03/The-Public-Health-Responsibility-Deal-March-20111.pdf (accessed 22 February 2018).

45. Knai C, Petticrew M, Durand MA, Eastmure E, Mays N. Are the Public Health Responsibility Deal alcohol pledges likely to improve public health? An evidence synthesis. Addiction 2015;110:1232-46. https://doi.org/10.1111/add.12855

46. Knai C, Petticrew M, Eastmure C, James L, Mehrotra A, Scott C, et al. The Public Health Responsibility deal: has a public-private partnership brought about action on alcohol reduction? Addiction 2015;110:1217-25. https://doi.org/10.1111/add.12892

47. Petticrew M, Eastmure E, Mays N, Knai C, Durand MA, Nolte E. The Public Health Responsibility Deal: how should such a complex public health policy be evaluated? J Public Health 2013;35:495-501. https://doi.org/10.1093/pubmed/fdt064

48. World Health Organization. Determinants of Health. Geneva: World Health Organization; 2017. URL: www.who.int/hia/evidence/doh/en/ (accessed 8 June 2017).

49. Cleland J, Watkins SC. The key lesson of family planning programmes for HIV/AIDS control. AIDS 2006;20:1-3. https://doi.org/10.1097/01.aids.0000194135.35758.cd

50. Government of Canada, Panel on Research Ethics. Tri-Council Policy Statement: Ethical Conduct for Research Involving Humans, Chapter 9: Research Involving the First Nations, Inuit and Métis Peoples of Canada. 2015. URL: www.pre.ethics.gc.ca/eng/policy-politique/initiatives/tcps2-eptc2/ chapter9-chapitre9/ (accessed 22 February 2018). 
51. Ofcom. HFSS Advertising Restrictions, Final Review. London: Ofcom; 2010. URL: www.ofcom.org. uk/_data/assets/pdf_file/0024/31857/hfss-review-final.pdf (accessed 22 February 2018).

52. Adams J, Tyrrell R, Adamson AJ, White M. Effect of restrictions on television food advertising to children on exposure to advertisements for 'less healthy' foods: repeat cross-sectional study. PLOS ONE 2012;7:e31578. https://doi.org/10.1371/journal.pone.0031578

53. Forget $E$. The town with no poverty: the health effects of a Canadian guaranteed annual income field experiment. Can Public Policy 2011;37:283-305. https://doi.org/10.3138/cpp.37.3.283

54. Forget E. Reconsidering a guaranteed annual income: lessons from MINCOME. Public Sector Digest, Fall 2015, pp. 18-23.

55. Wight $D$, Wimbush $E$, Jepson $R$, Doi L. Six steps in quality intervention development (6SQuID). J Epidemiol Community Health 2015. https://doi.org/10.1136/jech-2015-205952

56. Hawkins J, Madden K, Fletcher A, Midgley L, Grant A, Cox G, et al. Development of a framework for the co-production and prototyping of public health interventions. BMC Public Health 2017;17:689. https://doi.org/10.1186/s12889-017-4695-8

57. Edwards N, Kahwa E, Kaesje D, Mill J, Webber J, Roelofs S. Strengthening health care systems for HIV and AIDS in Sub-Saharan Africa and the Caribbean: a program of research. Caribb J Nurs Midwifery 2007;2:29-36.

58. Edwards N, Kaseje D, Kahwa E, Klopper HC, Mill J, Webber J, et al. The impact of leadership hubs on the uptake of evidence-informed nursing practices and workplace policies for HIV care: a quasi-experimental study in Jamaica, Kenya, Uganda and South Africa. Implement Sci 2016;11:110. https://doi.org/10.1186/s13012-016-0478-3

59. Rohwer A, Booth A, Pfadenhauer L, Brereton L, Gerhardus A, Mozygemba K, et al. Guidance on the Use of Logic Models in Health Technology Assessments of Complex Interventions. 2016.

URL: www.integrate-hta.eu/wp-content/uploads/2016/02/Guidance-on-the-use-of-logic-models-inhealth-technology-assessments-of-complex-interventions.pdf (accessed 22 February 2018).

60. De Silva MJ, Breuer E, Lee L, Asher L, Chowdhary N, Lund C, Patel V. Theory of change: a theorydriven approach to enhance the Medical Research Council's framework for complex interventions. Trials 2014;15:267. https://doi.org/10.1186/1745-6215-15-267

61. Breuer E, Lee L, De Silva M, Lund C. Using theory of change to design and evaluate public health interventions: a systematic review. Implement Sci 2016;11:63. https://doi.org/10.1186/ s13012-016-0422-6

62. Beeston C, McAdams R, Craig N, Gordon R, Graham L, MacPherson M, et al. Monitoring and Evaluating Scotland's Alcohol Strategy. Final Report. Edinburgh: NHS Health Scotland; 2016.

63. Licensing (Scotland) Act 2005. 2005 asp 16.

64. Scottish Government. Changing Scotland's Relationship with Alcohol: A Framework for Action. Edinburgh: Scottish Government; 2009.

65. Alcohol etc. (Scotland) Act 2010. 2010 asp 18.

66. Alcohol (Minimum Pricing) (Scotland) Act 2012. 2012 asp 4.

67. Bell CC, Bhana A, Petersen I, McKay MM, Gibbons R, Bannon W, Amatya A. Building protective factors to offset sexually risky behaviors among black youths: a randomized control trial. J Natl Med Assoc 2008;100:936-44. https://doi.org/10.1016/S0027-9684(15)31408-5

68. Bhana A, Petersen I, Mason A, Mahintsho Z, Bell C, McKay M. Children and youth at risk: adaptation and pilot study of the CHAMP (Amaqhawe) programme in South Africa. Afr J AIDS Res 2004;3:33-41. https://doi.org/10.2989/16085900409490316 
69. Paruk Z, Petersen I, Bhana A, Bell C, McKay M. Containment and contagion: how to strengthen families to support youth HIV prevention in South Africa. Afr J AIDS Res 2005;4:57-63. https://doi.org/10.2989/16085900509490342

70. Beenstock J, Sniehotta FF, White M, Bell R, Milne EM, Araujo-Soares V. What helps and hinders midwives in engaging with pregnant women about stopping smoking? A cross-sectional survey of perceived implementation difficulties among midwives in the North East of England. Implement Sci 2012;7:36. https://doi.org/10.1186/1748-5908-7-36

71. Bell R, Glinianaia SV, Waal ZV, Close A, Moloney E, Jones S, et al. Evaluation of a complex healthcare intervention to increase smoking cessation in pregnant women: interrupted time series analysis with economic evaluation. Tob Control 2018;27:90-8. https://doi.org/10.1136/ tobaccocontrol-2016-053476

72. Hunt K, McCann C, Gray C, Mutrie N, Wyke S. 'You've got to walk before you run'. Positive evaluations of a walking programme as part of a gender sensitised weight management programme delivered to men through professional football clubs. Health Psychol 2013;32:57-65. https://doi.org/10.1037/a0029537

73. Hunt K, Gray CM, Maclean A, Smillie S, Bunn C, Wyke S. Do weight management programmes delivered at professional football clubs attract and engage high risk men? A mixed-methods study. BMC Public Health 2014;14:50. https://doi.org/10.1186/1471-2458-14-50

74. Hunt K, Wyke S, Gray CM, Anderson AS, Brady A, Bunn C, et al. A gender-sensitised weight loss and healthy living programme for overweight and obese men delivered by Scottish Premier League football clubs (FFiT): a pragmatic randomised controlled trial. Lancet 2014;383:1211-21. https://doi.org/10.1016/S0140-6736(13)62420-4

75. Olds D, Henderson CR Jr, Tatelbaum R, Chamberlin R. Improving the delivery of prenatal care and outcomes of pregnancy: a randomized trial of nurse home visitation. Paediatrics 1986;77:16.

76. Kitzman H, Olds DL, Henderson CR Jr, Hanks C, Cole R, Tatelbaum R, et al. Effect of prenatal and infancy home visitation by nurses on pregnancy outcomes, childhood injuries, and repeated childbearing. A randomized controlled trial. JAMA 1997;278:644-52. https://doi.org/10.1001/ jama.1997.03550080054039

77. Olds DL, Robinson J, O’Brien R, Luckey DW, Pettitt LM, Henderson CR Jr, et al. Home visiting by paraprofessionals and by nurses: a randomized, controlled trial. Pediatrics 2002;110:486-96. https://doi.org/10.1542/peds.110.3.486

78. Mejdoubi J, van den Heijkant SCCM, van Leerdam FJM, Heymans MW, Crijnen A, Hirasing RA. The Effect of VoorZorg, the Dutch nurse-family partnership, on child maltreatment and development: a randomized controlled trial. PLOS ONE 2015;10:e0120182. https://doi.org/ 10.1371/journal.pone.0120182

79. Robling M, Bekkers MJ, Bell K, Butler CC, Cannings-John R, Channon S, et al. Effectiveness of a nurse-led intensive home-visitation programme for first-time teenage mothers (Building Blocks): a pragmatic randomised controlled trial. Lancet 2016;387:146-55. https://doi.org/10.1016/ s0140-6736(15)00392-X

80. Olds D. Building evidence to improve maternal and child health. Lancet 2016;387:105-7. https://doi.org/10.1016/s0140-6736(15)00476-6

81. Obasi Al, Cleophas B, Ross DA, Chima KL, Mmassy G, Gavyole A, et al. Rationale and design of the MEMA kwa Vijana adolescent sexual and reproductive health intervention in Mwanza Region, Tanzania. AIDS Care 2006;18:311-22. https://doi.org/10.1080/09540120500161983 
82. Doyle AM, Ross DA, Maganja K, Baisley K, Masesa C, Andreasen A, et al. Long-term biological and behavioural impact of an adolescent sexual health intervention in Tanzania: follow-up survey of the community-based MEMA kwa Vijana Trial. PLOS Med 2010;7:e1000287. https://doi.org/ 10.1371/journal.pmed. 1000287

83. Wight $D$, Plummer $M$, Ross $D$. The need to promote behaviour change at the cultural level: one factor explaining the limited impact of the MEMA kwa Vijana adolescent sexual health intervention in rural Tanzania. A process evaluation. BMC Public Health 2012;12:788. https://doi.org/10.1186/1471-2458-12-788

84. Charles C, Dewey K, Hall A, Hak C, Channary S, Summerlee A. A randomized control trial using a fish-shaped iron ingot for the amelioration of iron deficiency anaemia in rural Cambodian women. Trop Med Surg 2015;3:195. https://doi.org/10.4172/2329-9088.1000195

85. Charles CV, Dewey CE, Daniell WE, Summerlee AJ. Iron-deficiency anaemia in rural Cambodia: community trial of a novel iron supplementation technique. Eur J Public Health 2011;21:43-8. https://doi.org/10.1093/eurpub/ckp237

86. Lucky Iron Fish, Inc. Press Release: Lucky Iron Fish Update on Clinical Trial in Preah Vihear, Cambodia. URL: www.luckyironfish.com/blog/press-release-lucky-iron-fish-update-on-clinical-trial-in-preahvihear-cambodia (accessed 13 January 2017).

87. Oakley A, Strange V, Bonell C, Allen E, Stephenson J, RIPPLE Study Team. Process evaluation in randomised controlled trials of complex interventions. BMJ 2006;332:413-16. https://doi.org/ 10.1136/bmj.332.7538.413

88. Bonell C, Fletcher A, Morton M, Lorenc T, Moore L. Realist randomised controlled trials: a new approach to evaluating complex public health interventions. Soc Sci Med 2012;75:2299-306. https://doi.org/10.1016/j.socscimed.2012.08.032

89. Jamal F, Fletcher A, Shackleton N, Elbourne D, Viner R, Bonell C. The three stages of building and testing mid-level theories in a realist RCT: a theoretical and methodological case-example. Trials 2015;16:466. https://doi.org/10.1186/s13063-015-0980-y

90. Campbell R, Starkey F, Holliday J, Audrey S, Bloor M, Parry-Langdon N, et al. An informal school-based peer-led intervention for smoking prevention in adolescence (ASSIST): a cluster randomised trial. Lancet 2008;371:1595-602. https://doi.org/10.1016/S0140-6736(08)60692-3

91. Holliday J, Audrey S, Moore L, Parry-Langdon N, Campbell R. High fidelity? How should we consider variations in the delivery of school-based health promotion interventions? Health Educ J 2009;68:44-62. https://doi.org/10.1177/0017896908100448

92. Belaid L, Ridde V. Contextual factors as a key to understanding the heterogeneity of effects of a maternal health policy in Burkina Faso? Health Policy Plan 2015;30:309-21. https://doi.org/ 10.1093/heapol/czu012

93. De Allegri M, Tiendrebéogo J, Müller O, Yé M, Jahn A, Ridde V. Understanding home delivery in a context of user fee reduction: a cross-sectional mixed methods study in rural Burkina Faso. BMC Pregnancy Childbirth 2015;15:330. https://doi.org/10.1186/s12884-015-0764-0

94. Ridde V, Kouanda S, Yameogo M, Kadio K, Bado A. Why do women pay more than they should? A mixed methods study of the implementation gap in a policy to subsidize the costs of deliveries in Burkina Faso. Eval Program Plann 2013;36:145-52. https://doi.org/10.1016/ j.evalprogplan.2012.09.005

95. Goodman A, Sahlqvist S, Ogilvie D. New walking and cycling routes and increased physical activity: one- and two-year findings from the UK iConnect study. Am J Public Health 2014;104:e38-46. https://doi.org/10.2105/AJPH.2014.302059 
96. Panter J, Heinen E, Mackett R, Ogilvie D. Impact of New transport infrastructure on walking, cycling, and physical activity. Am J Prev Med 2016;50:e45-53. https://doi.org/10.1016/ j.amepre.2015.09.021

97. Panter J, Ogilvie D, iConnect Consortium. Theorising and testing environmental pathways to behaviour change: natural experimental study of the perception and use of new infrastructure to promote walking and cycling in local communities. BMJ Open 2015;5:e007593. https://doi.org/ 10.1136/bmjopen-2015-007593

98. Prins RG, Panter J, Heinen E, Griffin SJ, Ogilvie DB. Causal pathways linking environmental change with health behaviour change: natural experimental study of new transport infrastructure and cycling to work. Prev Med 2016;87:175-82. https://doi.org/10.1016/j.ypmed.2016.02.042

99. Kesten JM, Guell C, Cohn S, Ogilvie D. From the concrete to the intangible: understanding the diverse experiences and impacts of new transport infrastructure. Int J Behav Nutr Phys Act 2015;12:72. https://doi.org/10.1186/s12966-015-0230-4

100. Sahlqvist S, Goodman A, Jones T, Powell J, Song Y, Ogilvie D, iConnect Consortium. Mechanisms underpinning use of new walking and cycling infrastructure in different contexts: mixed-method analysis. Int J Behav Nutr Phys Act 2015;12:24. https://doi.org/10.1186/s12966-015-0185-5

101. Naimi Al, Kaufman JS, MacLehose RF. Mediation misgivings: ambiguous clinical and public health interpretations of natural direct and indirect effects. Int J Epidemiol 2014;43:1656-61. https://doi.org/10.1093/ije/dyu107

102. Kreiger N, Davey Smith G. The tale wagged by the DAG: broadening the scope of causal inference and explanation for epidemiology. Int J Epidemiol 2016;45:1787-1808. https://doi.org/ 10.1093/ije/dyw114

103. Edwards P, Steinbach R, Green J, Petticrew M, Goodman A, Jones A, et al. Health impacts of free bus travel for young people: evaluation of a natural experiment in London. J Epidemiol Community Health 2013;67:641-7. https://doi.org/10.1136/jech-2012-202156

104. Green J, Roberts H, Petticrew M, Steinbach R, Goodman A, Jones A, et al. Integrating quasiexperimental and inductive designs in evaluation: a case study of the impact of free bus travel on public health. Evaluation 2015;21:391-406. https://doi.org/10.1177/1356389015605205

105. Hoffmann TC, Glasziou PP, Boutron I, Milne R, Perera R, Moher D, et al. Better reporting of interventions: template for intervention description and replication (TIDieR) checklist and guide. BMJ 2014;348:g1687. https://doi.org/10.1136/bmj.g1687

106. Schulz K, Altman D, Moher D, for the CONSORT Group. CONSORT 2010 statement: updated guidelines for reporting parallel group randomised trials. BMJ 2010;340:c332. https://doi.org/ 10.1136/bmj.c332

107. von Elm E, Altman D, Egger M, Pocock S, Gotzsche P, Vandenbroucke J. The Strengthening the Reporting of Observational Studies in Epidemiology (STROBE) statement: guidelines for reporting observational studies. BMJ 2007;335:806-8. https://doi.org/10.1136/bmj.39335.541782.AD

108. Des Jarlais DC, Lyles C, Crepaz N, TREND group. Improving the reporting quality of nonrandomized evaluations of behavioral and public health interventions: the TREND statement. Am J Public Health 2004;94:361-6. https://doi.org/10.2105/AJPH.94.3.361

109. Burchett $H$, Umoquit M, Dobrow M. How do we know when research from one setting can be useful in another? A review of external validity, applicability and transferability frameworks. J Health Serv Res Policy 2011;16:238-44. https://doi.org/10.1258/jhsrp.2011.010124

110. Zwarenstein M, Treweek S, Gagnier JJ, Altman DG, Tunis S, Haynes B, et al. Improving the reporting of pragmatic trials: an extension of the CONSORT statement. BMJ 2008;337:a2390. https://doi.org/10.1136/bmj.a2390

(c) Queen's Printer and Controller of HMSO 2018. This work was produced by Craig et al. under the terms of a commissioning contract issued by the Secretary of State for Health and Social Care. This issue may be freely reproduced for the purposes of private research and study and extracts (or indeed, the full report) may be included in professional journals provided that suitable acknowledgement is made and the reproduction is not associated with any form of advertising. Applications for commercial reproduction should be addressed to: NIHR Journals Library, National Institute for Health Research, Evaluation, Trials and Studies Coordinating Centre, Alpha House, University of Southampton Science Park, Southampton SO16 7NS, UK. 
111. Hales S, Lesher-Trevino A, Ford N, Maher D, Ramsay A, Tran N. Reporting guidelines for implementation and operational research. Bull World Health Organ 2016;94:58-64. https://doi.org/10.2471/BLT.15.167585

112. Pinnock H, Epiphaniou E, Sheikh A, Griffiths C, Eldridge S, Craig P, Taylor SJ. Developing standards for reporting implementation studies of complex interventions (StaRI): a systematic review and e-Delphi. Implement Sci 2015;10:42. https://doi.org/10.1186/s13012-015-0235-z

113. Mackay DF, Irfan MO, Haw S, Pell JP. Meta-analysis of the effect of comprehensive smoke-free legislation on acute coronary events. Heart 2010;96:1525-30. https://doi.org/10.1136/ hrt.2010.199026

114. Mwansa-Kambafwile J, Cousens S, Hansen T, Lawn JE. Antenatal steroids in preterm labour for the prevention of neonatal deaths due to complications of preterm birth. Int J Epidemiol 2010;39(Suppl. 1):i122-33. https://doi.org/10.1093/ije/dyq029

115. Azad K, Costello A. Extreme caution is needed before scale-up of antenatal corticosteroids to reduce preterm deaths in low-income settings. Lancet Glob Health 2014;2:e191-2. https://doi.org/10.1016/S2214-109X(14)70020-8

116. Althabe F, Belizán JM, McClure EM, Hemingway-Foday J, Berrueta M, Mazzoni A, et al. A population-based, multifaceted strategy to implement antenatal corticosteroid treatment versus standard care for the reduction of neonatal mortality due to preterm birth in low-income and middle-income countries: the ACT cluster-randomised trial. Lancet 2015;385:629-39. https://doi.org/10.1016/S0140-6736(14)61651-2

117. Gibson M, Thomson H, Banas K, Bambra C, Fenton C, Bond L. Welfare to work interventions and their effects on health and well-being of lone parents and their children. Cochrane Database Syst Rev 2017;8:CD009820.

118. Langford R, Bonell CP, Jones HE, Pouliou T, Murphy SM, Waters E, et al. The WHO Health Promoting School framework for improving the health and well-being of students and their academic achievement. Cochrane Database Syst Rev 2014;4:CD008958. https://doi.org/10.1002/ 14651858.CD008958.pub2

119. Langford R, Bonell C, Jones H, Pouliou T, Murphy S, Waters E, et al. The World Health Organization's Health Promoting Schools framework: a Cochrane systematic review and meta-analysis. BMC Public Health 2015;15:130. https://doi.org/10.1186/s12889-015-1360-y

120. Armstrong R, Waters $E$, on behalf of the Guidelines for Systematic Reviews in Health Promotion and Public Health Taskforce. Guidelines for Systematic Reviews of Health Promotion and Public Health Interventions. Version 2. Melbourne: Melbourne University; 2007.

121. Whitty CJ. What makes an academic paper useful for health policy? BMC Med 2015;13:301. https://doi.org/10.1186/s12916-015-0544-8

122. Humphreys DK, Panter J, Ogilvie D. Questioning the application of risk of bias tools in appraising evidence from natural experimental studies: critical reflections on Benton et al. Int J Behav Nutr Phys Act 2017;14:49. https://doi.org/10.1186/s12966-017-0500-4

123. Becker BJ, Aloe AM, Duvendack M, Stanley TD, Valentine JC, Fretheim A, Tugwell P. Quasiexperimental study designs series-paper 10: synthesizing evidence for effects collected from quasi-experimental studies presents surmountable challenges. J Clin Epidemiol 2017;89:84-91. https://doi.org/10.1016/j.jclinepi.2017.02.014

124. Pawson R. Evidence-based Policy. A Realist Perspective. London: Sage; 2006. https://doi.org/ $10.4135 / 9781849209120$

125. Noblit G, Hare R. Meta-ethnography: Synthesizing Qualitative Studies. London: Sage; 1988. https://doi.org/10.4135/9781412985000 
126. O'Campo P, Molnar A, Ng E, Renahy E, Mitchell C, Shankardass K, et al. Social welfare matters: a realist review of when, how, and why unemployment insurance impacts poverty and health. Soc Sci Med 2015;132:88-94. https://doi.org/10.1016/j.socscimed.2015.03.025

127. Jamal F, Fletcher A, Harden A, Wells H, Thomas J, Bonell C. The school environment and student health: a systematic review and meta-ethnography of qualitative research. BMC Public Health 2013;13:798. https://doi.org/10.1186/1471-2458-13-798

128. McGill R, Anwar E, Orton L, Lloyd-Williams F, O'Flaherty M, Bromley H, et al. Are interventions to promote healthy eating equally effective for all? Systematic review of socio-economic inequalities in impact. BMC Public Health 2015;15:457. https://doi.org/10.1186/s12889-015-1781-7

129. Forrest L, Adams J, Wareham H, Rubin G, White M. Socioeconomic inequalities in lung cancer treatment: systematic review and meta-analysis. PLOS Med 2013;10:e1001376. https://doi.org/ 10.1371/journal.pmed. 1001376

130. University of Victoria, Centre for Indigenous Research and Community-led Engagement. Visioning Health. 2018. URL: www.uvic.ca/research/centres/circle/research/visioning-health-ii/index.php (accessed 22 February 2018).

131. Harrowing JN, Edwards N, Richter S, Minnie K, Rae T. African and Caribbean nurses' decisions about HIV testing: a mixed methods study [published online ahead of print 24 July 2017]. AIDS Behav 2017. https://doi.org/10.1007/s10461-017-1862-y

132. Harrowing JN, Mill J. Moral distress among Ugandan nurses providing HIV care: a critical ethnography. Int J Nurs Stud 2010;47:723-31. https://doi.org/10.1016/j.ijnurstu.2009.11.010

133. Juma PA, Edwards N, Spitzer D. Kenyan nurses involvement in national policy development processes. Nurs Res Pract 2014;2014:236573. https://doi.org/10.1155/2014/236573

134. Yassi A, O'Hara LM, Lockhart K, Spiegel JM. Workplace programmes for HIV and tuberculosis: a systematic review to support development of international guidelines for the health workforce. AIDS Care 2013;25:525-43. https://doi.org/10.1080/09540121.2012.712668

135. Mill J, Davison C, Richter S, Etowa J, Edwards N, Kahwa E, et al. Qualitative research in an international research program: maintaining momentum while building capacity in nurses. Int J Qual Methods 2014;13:151-69. https://doi.org/10.1177/160940691401300105

136. Bender A, Edwards N, Kahwa E, Kaseje D. Developing capacity through a participatory action research approach. In Edwards N, Kaseje D, Kahwa E, editors. Building and Evaluating Research Capacity in Context: Case Studies of Innovative Models in Global Health. Cape Town: University of Cape Town Press; 2016.

137. Edwards N, Kahwa E, Hoogeveen K. Results of an Integrative Analysis: A Call for Contextualizing HIV and AIDS Clinical Practice Guidelines to Support Evidence-Based Practice. Worldviews Evid Based Nurs 2017;14:492-8. https://doi.org/10.1111/wvn.12247

138. McKay MM, Chasse KT, Paikoff R, McKinney LD, Baptiste D, Coleman D, et al. Family-level Impact of the CHAMP family program: a community collaborative effort to support urban families and reduce youth HIV risk exposure. Fam Process 2004;43:79-93. https://doi.org/10.1111/ j.1545-5300.2004.04301007.x

139. Graham H, Flemming K, Fox D, Heirs M, Sowden A. Cutting down: insights from qualitative studies of smoking in pregnancy. Health Soc Care Community 2014;22:259-67. https://doi.org/ 10.1111/hsc. 12080 
140. Gray CM, Hunt K, Mutrie N, Anderson AS, Leishman J, Dalgarno L, Wyke S. Football Fans in Training: the development and optimization of an intervention delivered through professional sports clubs to help men lose weight, become more active and adopt healthier eating habits. BMC Public Health 2013;13:232. https://doi.org/10.1186/1471-2458-13-232

141. Wyke S, Hunt K, Gray C, Fenwick E, Bunn C, Donnan P, et al. Football Fans in Training (FFiT): a randomised controlled trial of a gender-sensitised weight loss and healthy living programme for men - end of study report. Public Health Res 2015;3(2).

142. Bunn C, Wyke S, Gray CM, Maclean A, Hunt K. 'Coz football is what we all have': masculinities, practice, performance and effervescence in a gender-sensitised weight-loss and healthy living programme for men. Sociol Health IIIn 2016;38:812-28. https://doi.org/10.1111/14679566.12402

143. Audrey S, Holliday J, Campbell R. Commitment and compatibility: teachers' perspectives on the implementation of an effective school-based, peer-led smoking intervention. Health Educ J 2009;67:74-90. https://doi.org/10.1177/0017896908089387

144. Audrey S, Holliday J, Campbell R. It's good to talk: adolescent perspectives of an informal, peer-led intervention to reduce smoking. Soc Sci Med 2006;63:320-34. https://doi.org/10.1016/ j.socscimed.2005.12.010

145. Hafeman DM. A sufficient cause based approach to the assessment of mediation. Eur J Epidemiol 2008;23:711-21. https://doi.org/10.1007/s10654-008-9286-7

146. VanderWeele TJ. Mediation and mechanism. Eur J Epidemio/ 2009;24:217-24. https://doi.org/ 10.1007/s10654-009-9331-1 